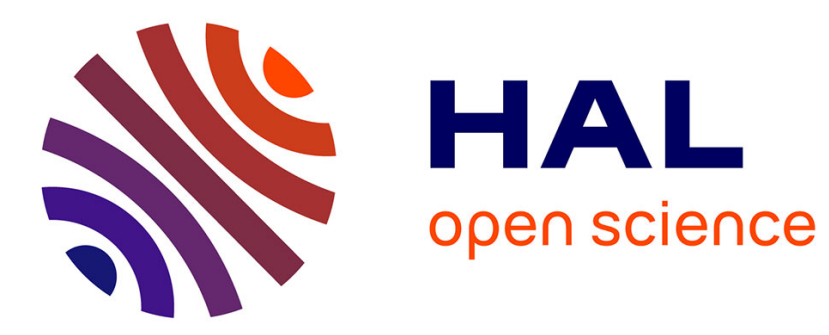

\title{
Metal complexes for multimodal imaging of misfolded protein-related diseases
}

S. Lacerda, J.-F. Morfin, C. F G C Geraldes, É. Tóth

\section{To cite this version:}

S. Lacerda, J.-F. Morfin, C. F G C Geraldes, É. Tóth. Metal complexes for multimodal imaging of misfolded protein-related diseases. Dalton Transactions, 2017, 46 (42), pp.14461-14474. 10.1039/C7DT02371E . hal-02068723

\section{HAL Id: hal-02068723}

\section{https://hal.science/hal-02068723}

Submitted on 18 Feb 2022

HAL is a multi-disciplinary open access archive for the deposit and dissemination of scientific research documents, whether they are published or not. The documents may come from teaching and research institutions in France or abroad, or from public or private research centers.
L'archive ouverte pluridisciplinaire HAL, est destinée au dépôt et à la diffusion de documents scientifiques de niveau recherche, publiés ou non, émanant des établissements d'enseignement et de recherche français ou étrangers, des laboratoires publics ou privés. 


\title{
Journal Name
}

\section{ARTICLE}

\section{Metal complexes for multimodal imaging of misfolded protein- related diseases}

Received 00th January 20xx, Accepted 00th January 20xx

DOI: $10.1039 / x 0 x \times 00000 x$

www.rsc.org/

\author{
S. Lacerda, ${ }^{* a}$ J-F. Morfin, ${ }^{a}$ C.F.G.C. Geraldes ${ }^{b, c}$ and É. Tóth ${ }^{* a}$
}

\begin{abstract}
Aggregation of misfolded proteins and progressive polymerization of otherwise soluble proteins is a common hallmark of a wide range of highly debilitating and increasingly prevalent diseases, including Amyotrophic Lateral Sclerosis, Cerebral Amyloid Angiopathy, Type II Diabetes and Parkinson's, Huntington's and Alzheimer's diseases. There is a growing interest in creating imaging agents to detect such aggregates in various imaging modalities, including PET, SPECT and MRI. We present here an overview of recent efforts in the perspective of early diagnosis of amyloid diseases, with a major focus on $A \beta$ detection and on metal complexes bearing PiB units.
\end{abstract}

\section{Introduction}

Protein folding and unfolding processes govern biological activity in multiple ways. Proteins, only when correctly folded, have long-term stability in complex biological environments and are capable of interacting selectively with their natural partners. ${ }^{1}$ The way a newly synthesized chain of amino acids converts into a perfectly folded protein depends both on the intrinsic properties of the amino-acid sequence and on multiple factors of the cellular milieu. In vitro parameters inducing aggregation may include temperature, $\mathrm{pH}$, co-solvent, metal ions, surfactants etc; while in vivo factors imply mutation in the polypeptide chain, translational error, ageing and inability of cellular machinery to clear the aggregates. Water has a dual role: it protects the disordered peptide-chain by hydration but also helps globular chain-folding, stimulating protein aggregation. Metal ions (namely $\mathrm{Cu}^{2+}, \mathrm{Zn}^{2+}$ and $\mathrm{Fe}^{3+}$ ) also play a crucial role in the aggregation process, being therefore intrinsically connected to the onset and development of some neurodegenerative disorders. ${ }^{2-4}$

Amyloidogenesis is the process where folded, globular proteins unfold or misfold (thus avoid the protein quality control and degradation system) and then misassemble into soluble and insoluble toxic oligomer/polymer cross- $\beta$-sheet fibrillary aggregates, known as amyloids. ${ }^{3}$ In addition to the toxic oligomeric species, reactive oxygen species are generated during aggregation contributing also to

\footnotetext{
a. Centre de Biophysique Moléculaire, CNRS, UPR 4301, Université d'Orléans, Rue Charles Sadron, 45071 Orléans Cedex 2, France.

${ }^{b .}$ Department of Life Sciences, Faculty of Sciences and Technology, University of Coimbra, Calçada Martim de Freitas, 3000-393 Coimbra, Portugal.

c. Coimbra Chemistry Center, University of Coimbra, Rua Larga, 3004-535 Coimbra, Portugal

*Corresponding authors: sara.lacerda@cnrs.fr; eva.jakabtoth@cnrs.fr See DOI: 10.1039/x0xx00000x
}

cytotoxicity. Since aggregation is not a synchronized process, monomers, oligomers and fibrils co-exist with different physiological clearance rates for different species. The preexisting fibrils can be further fragmentized into small pieces which act as new oligomeric nuclei to amplify aggregation. This process is known as "secondary nucleation" and has been identified in the case of $\alpha$ synuclein and $A \beta .^{5}$ Figure 1 shows a schematic representation of the protein aggregation pathway.

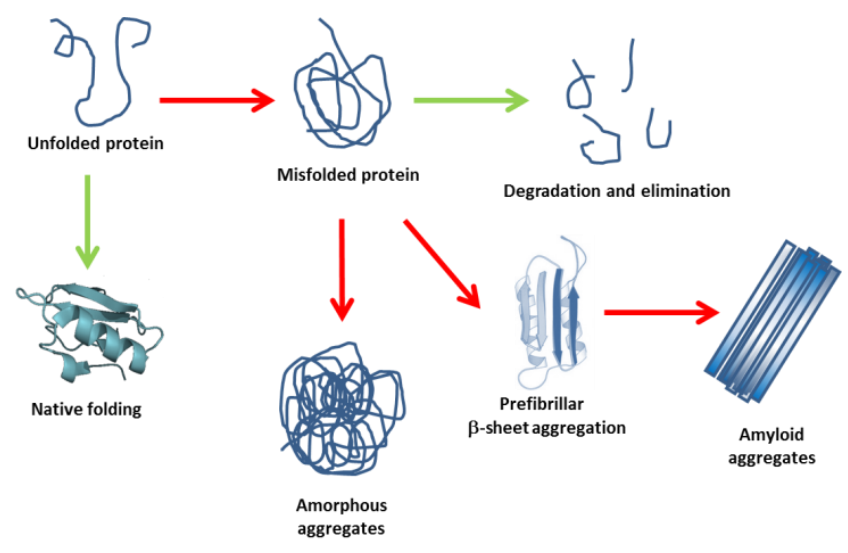

Figure 1: Schematic illustration of protein aggregation in amyloid disorders. Green and red arrows correspond to normal and abnormal processes, respectively.

Aggregation of misfolded proteins and progressive polymerization of otherwise soluble proteins is a common hallmark of a wide range of highly debilitating and increasingly prevalent diseases. Indeed, about 30 different diseases are known to date to be related to protein misfolding and amyloidogenesis, including Prion Disease, Amyotrophic Lateral Sclerosis, Cerebral Amyloid Angiopathy, Type II Diabetes and Parkinson's, Huntington's 
and Alzheimer's diseases (Table 1). These aggregation processes are associated with profound cell/organ dysfunction and death, triggering lethal effects, such as ubiquitin proteasome system failure, lipid membrane permeability, oxidative stress, endoplasmic reticulum stress and mitochondrial dysfunction. ${ }^{5,} 6$ Importantly, amyloidogenesis precedes the earliest clinical signs of the diseases thus can be a relevant biomarker for diagnostic imaging.

Table 1: Misfolded proteins and related diseases

\begin{tabular}{|c|c|}
\hline Disease & Misfolded protein \\
\hline \multirow[t]{2}{*}{$\begin{array}{l}\text { Amyotrophic } \\
\text { Sclerosis (ALS) }\end{array}$} & $\begin{array}{l}\text { Superoxide } \\
\text { (SOD1) }\end{array}$ \\
\hline & $\begin{array}{l}\text { TAR-DNA-binding protein } 43 \\
\text { (TDP-43) }\end{array}$ \\
\hline $\begin{array}{l}\text { Cerebral } \\
\text { Angiopathy (CAA) }\end{array}$ & Amyloid- $\beta$ (Aß) \\
\hline Type II Diabetes (T2D) & Human amylin \\
\hline Parkinson's disease (PD) & $\alpha$-Synuclein ( $\alpha$-syn) \\
\hline Huntington disease (HD) & Polyglutamine proteins \\
\hline \multirow[t]{2}{*}{ Alzheimer's disease (AD) } & Amyloid- $\beta$ \\
\hline & $\begin{array}{l}\text { Hyperphosphorilated } \\
\text { protein }\end{array}$ \\
\hline
\end{tabular}

It is still unclear whether inhibiting the oligomerization of the implicated proteins will actually prevent the clinical syndromes. Moreover, it has recently been reported that the proteins $A \beta$, tau (whose hyperphosphorylation induces protein aggregation) and $\alpha$-syn interact in vivo, promoting the accumulation of one another, leading to heteroaggregation and accelerating cognitive dysfunction.

The in vivo toxicity of the amyloid proteins seems to depend on their aggregation level. Amyloid toxicity has been related to various mechanisms, namely: generation of reactive oxygen species, overloading of the misfolded protein response pathway, interaction with cell receptors, interaction with metal ions and the capacity of amyloid proteins to interact and disrupt cell membranes. ${ }^{7-9}$ The antiparallel $\beta$-sheet structure of short oligomers and/or fibers interact with cell membranes and promote their disruption in a two-step mechanism: (i) binding to the membrane with formation of a ion permeable pores, and (ii) membrane fragmentation via a detergent-like mechanism (due to the $A \beta$ fibrillization). Recently, it has been shown that the reduced pathological lipid bilayer thickness, which occurs in vivo in case of $A D$ by initial aggregation and strain or incorporation of peroxidized lipids, is capable of altering the aggregation pathway of $A \beta$ and to stabilize distinct membrane-associated intermediate aggregates. ${ }^{10}$
Currently, pathological examination of the postmortem brain tissue is the sole definitive diagnostic method for most neurodegenerative misfolded protein-related diseases, with no pre-onset diagnosis available. The conspicuous similarities and the common neuropathological hallmarks of these diseases, namely extracellular amyloid plaque deposition in the brain, make their accurate and early diagnostic very difficult. ${ }^{11,12}$

To monitor brain neurodegeneration, structural magnetic resonance imaging (MRI) studies of hippocampal and adjacent cortical atrophy are widely used. The morphological changes in the brain are accompanied by reactive gliosis, diffuse synaptic and neuronal loss, and by the presence of the pathological hallmarks of the disease: intracellular neurofibrillary tangles (NFT) and extracellular amyloid plaques. ${ }^{12,13}$ Other biomarkers include increased cerebrospinal fluid (CSF) total tau concentration and hypometabolism, the latter typically assessed by ${ }^{18} \mathrm{~F}$-fluorodeoxy glucose $\left(\left[{ }^{18} \mathrm{~F}\right]-\mathrm{FDG}\right)$ positron emission tomography (PET).

Molecular imaging could play a central role in the early detection of misfolded protein pathologies and contribute (i) to an accurate diagnosis, (ii) to reveal new mechanisms and pathways in cell biology, (iii) to improve our understanding of disease and disease progression, and (iv) to the development of novel therapeutic strategies. In terms of molecular imaging, nuclear imaging techniques, such as PET and single photon emission computed tomography (SPECT), are used for visualization of amyloid deposits, as well as metabolic deficiencies in the brain, with imaging probes already in clinical use. PET and SPECT are molecular imaging techniques that rely on the detection of radioactivity of positron- or gamma- emitting isotopes that are incorporated into a molecular tracer. In PET, the emitted positron annihilates releasing two gamma photons travelling in opposite directions, with an energy of $511 \mathrm{KeV}$. Detection of the emitted photons allows the generation of an image with a spatial resolution of 3-5 $\mathrm{mm}$ in a clinical scanner and with high sensitivity (probe concentrations in pico-nanomolar range). In SPECT, the isotopes used have in general longer half-lives and therefore offer a longer imaging window. In SPECT, it is possible to image two or more radio-labelled probes simultaneously using energy discrimination, but it has lower sensitivity than PET (more than an order of magnitude). ${ }^{14}$

Molecular probes for near infrared fluorescence imaging have been also proposed. Optical imaging has the limitation of low depth penetration and clinical translation for in vivo imaging of amyloid diseases seems compromised. On the other hand, it is rapid and inexpensive, which makes it well adapted for pre-clinical studies. The use of probes emitting in the near infrared region (600-1000 nm) allows for improved photon penetration through tissue and minimizes the effects of light scattering and tissue autofluorescence. ${ }^{15}$ 
MRI is a powerful clinical and biological imaging tool, based on magnetic resonance signals produced by body nuclear spins. MRI signal intensity depends on local spin density, mainly of water and fat protons, but can also be made dependent on proton longitudinal $\left(T_{1}\right)$ and transverse $\left(T_{2}\right)$ relaxation times as well as on $T_{2}{ }^{*}$ relaxation times, which also reflect the effect of local magnetic field anisotropies. MRI offers non-invasive anatomical and functional information with excellent spatial resolution (50-200 $\mu \mathrm{m}$ for research and clinical scanners). Such high resolution can be relevant for detection and quantification of small amyloid lesions. Other advantages of MRI relative to nuclear techniques are wider availability and absence of radiation burden. However, a major limitation of MRI is its low sensitivity. This can be circumvented by increasing the magnetic field, using longer acquisition times or more sensitive pulse sequences, injecting hyperpolarized tracers and most commonly, applying exogenous contrast agents (CAs). These agents act by decreasing the relaxation times of tissue water protons in the body regions where they distribute. Due to its high electron spin and slow electronic relaxation, $\mathrm{Gd}^{3+}$ is the most efficient paramagnetic ion to increase the water proton relaxation rate $\left(1 / T_{1}\right)$, generating a positive contrast in $T_{1}$ weighted images. Clinical CAs are stable $\mathrm{Gd}^{3+}$ complexes of linear or macrocyclic polyamino carboxylate ligands. Their MRI efficiency is measured by the longitudinal relaxivity, $r_{1}$, defined as the paramagnetic enhancement of longitudinal water proton relaxation rate normalized to $1 \mathrm{mM}$ concentration. It is determined by several microscopic parameters of the complex, the most important being the number and the exchange rate of the water molecules in the inner coordination sphere of the $\mathrm{Gd}^{3+}$ ( $\mathrm{q}$ and $k_{\mathrm{ex}}$ ), the rotational correlation time $\left(\tau_{\mathrm{R}}\right)$ of the complex and the relaxation times of the $\mathrm{Gd}^{3+}$ electron spin $\left(\mathrm{T}_{1,2 \mathrm{e}}\right)$. In addition to high relaxivity, $\mathrm{Gd}^{3+}$-based MRI agents have to possess high in vivo thermodynamic stability and kinetic inertness to avoid toxicity, as well as appropriate biodistribution to achieve suitable target imaging. Superparamagnetic iron oxide nanoparticles are composed by thousands of $\mathrm{Fe}_{3} \mathrm{O}_{4}$ and $\gamma-\mathrm{Fe}_{2} \mathrm{O}_{3}$ nanocrystals and enhance primarily the $1 / T_{2}$ relaxation rate, providing a negative image contrast in $T_{2}$ and $T_{2} *$ weighted images. They typically provide higher sensitivity and can be visualized at lower concentrations than $\mathrm{Gd}^{3+}$ chelates. ${ }^{16}$

Several recent reviews are available on biomarkers and imaging probes for amyloid- $\beta$ detection in Alzheimer's disease. ${ }^{11,12,17-19}$ In this Perspective paper, we would like to highlight the versatile potential of metal complexes as multimodal imaging agents in a variety of pathologies related to protein misfolding, well beyond $A D$ which has been so far mostly explored in this context. Indeed, the majority of experimental data are available for $\beta$-amyloid detection. These will be surveyed here with a specific focus on PiB-derivative metal chelates.

\section{Imaging of misfolded protein-based diseases}

Protein aggregates have been explored as biomarkers for both diagnostic and therapeutic purposes over the past years. In addition to $A D$, these studies involved other pathologies implicating misfolded proteins, namely Parkinson's disease, Amyotrophic Lateral Sclerosis, Huntington's Disease, Cerebral Amyloid Angiopathy and Type 2 diabetes mellitus and aimed either at the design of dedicated novel probes or the use of contrast agents which were previously tested for AD. The majority of the imaging agents reported is based on ${ }^{18} \mathrm{~F},{ }^{11} \mathrm{C}$ or ${ }^{125} \mathrm{I}$ derivatives of blood brain barrier (BBB) permeable small organic molecules, whose structures are derived from thioflavin-T, benzoxazoles and stilbenes. Such derivatives have been shown to target the aggregated forms of $A \beta .^{12}$ Currently in phase III clinical trials, the first tracer with high affinity and selectivity for fibrillar $A \beta$ was ${ }^{11} \mathrm{C}-\mathrm{PiB}$ (a thioflavin- $\mathrm{T}$ derivative), which is becoming the gold standard for $A \beta$ imaging. Nevertheless, its carbon-11 labeling, with a halflife of $\mathbf{2 0 . 4}$ minutes and the need of an onsite cyclotron and extensive radiochemistry capabilities, restricts the use of this probe to sophisticated centers. The development of comparable fluorine-18 labeled tracers enables widespread $A \beta$ imaging. Among the numerous compounds developed for visualization of $A \beta$ aggregates, three probes have been approved by the European Medicines Agency and the Food and Drug Administration in the USA: $\left[{ }^{18} \mathrm{~F}\right]$-florbetapir (Amyvid $\left.{ }^{\circledR}\right), \quad\left[{ }^{18} \mathrm{~F}\right]$-flutemetamol $\left(\right.$ Vizamyl $\left.^{\circledR}\right)$, and $\left[{ }^{18} \mathrm{~F}\right]-$ florbetaben (Neuraceq ${ }^{\circledR}$ ). ${ }^{11,12}$

We should also note that various small molecular compounds have been also used as chemical tools to interrogate metal-A $\beta$ interaction and the associated aggregation. $^{20}$ Some of these compounds can be also exploited to create imaging probes.

More recently, there has been an increasing interest in using metal complexes for nuclear $\left({ }^{99 \mathrm{~m}} \mathrm{Tc},{ }^{111} \mathrm{In},{ }^{68} \mathrm{Ga},{ }^{64} \mathrm{Cu}\right.$, ${ }^{89} \mathrm{Zr}$ ) or MR imaging (Gd). Various ligands and targeting units have been explored for the optimization of the biodistribution, affinity, selectivity and in vivo half-life of the probes, in the objective of achieving wider applicability.

A major advantage of metal based imaging probes is their versatility. Indeed, the same chelating framework can be used to form stable complexes with a large variety of metal ions, including those with appropriate magnetic properties for MRI, radioactive isotopes adapted to nuclear imaging and even luminescent metal ions for optical detection. In nuclear imaging, metal isotopes offer a great choice of emission mode and half-life. On the other hand, a potential disadvantage of metal complexes in this field can be their molecular size, which is typically larger than that of ${ }^{11} \mathrm{C}$ - or ${ }^{18} \mathrm{~F}$-labelled small tracers and which can prevent efficient BBB permeability in case of brain imaging. Finally, the conjugation of a relatively bulky metal complex to a protein recognition unit can also lead to a decreased affinity to the protein. 
Parkinson's Disease represents the second most common neurodegenerative disorder with an estimated global prevalence of over 10 million. The underlying molecular features include abnormal $\alpha$-syn accumulation in intra- and interneuronal inclusions (Lewy bodies and Lewy neurites, respectively) along with degeneration of substantia nigra dopaminergic neurons. $\alpha$-syn is a small (140 amino acids), highly soluble presynaptic protein that normally exists in a natively unfolded state. In PD, its conformation changes to $\alpha$-helical fibrils and oligomers that form $\beta$-sheet rich fibrils. This resultant protein aggregation sets the "misfolded hypothesis" of PD. These aggregates can also migrate from affected to unaffected neurons, causing further misfolding. 21,22

PET tracers used in PD imaging include labelled organic molecules: $\left[{ }^{18} \mathrm{~F}\right]-\mathrm{DOPA}$ to visualize dopamine synthesis, $\left[{ }^{11} \mathrm{C}\right]$-b-CFT for dopamine transporter, $\left[{ }^{11} \mathrm{C}\right]-\mathrm{DTBZ}$ for vesicular monoamine transporter type $2,\left[{ }^{11} \mathrm{C}\right]$-raclopride for D2 receptor, $\left[{ }^{11} \mathrm{C}\right]$-WAY100635 for serotonin receptor, $\left[{ }^{11} \mathrm{C}\right]-\mathrm{PBR} 28$ for translocator protein, $\left[{ }^{11} \mathrm{C}\right]-\mathrm{HG}-10-102-01$ for detection of enzyme LRRK2, $\left[{ }^{18} \mathrm{~F}\right]-\mathrm{T} 807$ ( $\left.\left[{ }^{18} \mathrm{~F}\right]-\mathrm{AV}-1451\right)$ for tau protein and $\left[{ }^{11} \mathrm{C}\right]$-PIB for aggregated $\beta$-amyloid plaques. SPECT tracers include [ $\left.{ }^{123} \mathrm{I}\right]$-FP-CIT for assessment of the integrity of nigrostriatal dopaminergic system and cerebral perfusion changes, and $\left[{ }^{123} \mathrm{I}\right]-$ IBZM which helps differentiating PD from atypical Parkinsonism. The only metal-based tracers used for PD imaging include [ $\left.{ }^{99 m} \mathrm{Tc}\right] \mathrm{ECD}$ (ethyl cysteinate diethylester) and $\left[{ }^{99 \mathrm{~m}} \mathrm{Tc}\right] \mathrm{HMPAO}$ (hexamethylpropyleneamine oxime) ${ }^{23-25}$ to assess cerebral perfusion changes. The majority of these probes do not target misfolded protein aggregates. Developing an $\alpha$-syn tracer poses a great challenge, but would help distinguishing PD from other disorders. Like tau, aggregated $\alpha$-syn is far less abundant in the brain than $A \beta$, requiring very high selectivity for $\alpha$-syn over $A \beta$ and tau. Moreover, like tau, $\alpha$-syn accumulates mainly intracellularly, with some $\alpha$-syn found extracellularly, either as a consequence of neuronal death or due to secretion from neurons and spreading in a prion-like manner. ${ }^{22,26}$

Recently, a series of PET tracers have been proposed to target $\alpha$-syn, based on molecules with high affinity for $\alpha$ syn, $A \beta$ and tau fibrils. The ${ }^{11} C$ and ${ }^{125}$ I radiolabeling of the phenothiazine analogues SIL5 and SIL26, respectively, yielded a PET and SPECT tracer that cross the BBB in healthy adult male rats. $\left[{ }^{11} \mathrm{C}\right]-\mathrm{SL} 5$ showed also brain uptake in healthy cynomolgus monkey, representing a promising probe for further in vivo $\alpha$-syn imaging studies. ${ }^{22}$

Huntington's Disease (HD) is an autosomal dominant monogenic neurodegenerative disease characterized by a CAG trinucleotide repeat expansion in the huntingtin gene, which results in a lengthened polyglutamine chain on huntingtin protein, leading to its abnormal neuronal aggregation. ${ }^{27} \mathrm{HD}$ has been indirectly assessed based on biomarkers which include: brain metabolism (using $\left[{ }^{18} \mathrm{~F}\right]-$ FDG and $\left.\left[{ }^{15} \mathrm{O}\right]-\mathrm{H} 2 \mathrm{O}\right)$, presynaptic $\left(\left[{ }^{18} \mathrm{~F}\right]-\mathrm{DOPA},\left[{ }^{11} \mathrm{C}\right]-\beta-\mathrm{CIT}\right.$ and $\left[{ }^{11} \mathrm{C}\right]$-DTBZ) and postsynaptic $\left(\left[{ }^{11} \mathrm{C}\right]-\mathrm{SCH} 22390,\left[{ }^{11} \mathrm{C}\right]-\right.$ FLB457 and $\left[{ }^{11} \mathrm{C}\right]$-raclopride) dopaminergic function, phosphodiesterases ( $\left[{ }^{18} \mathrm{~F}\right]-\mathrm{JNJ} 42259152,\left[{ }^{18} \mathrm{~F}\right]-\mathrm{MNI}-659$ and $\left.\left[{ }^{11} \mathrm{C}\right]-I M A 107\right)$, and adenosine ([ $\left.\left.{ }^{18} \mathrm{~F}\right]-\mathrm{CPFPX}\right)$, cannabinoid ([ $\left.\left.{ }^{18} \mathrm{~F}\right]-\mathrm{MK}-9470\right)$, opioid $\left(\left[{ }^{11} \mathrm{C}\right]\right.$-diprenorphine) and GABA ([ $\left.{ }^{11} \mathrm{C}\right]$-flumazenil) receptors. ${ }^{25}$ Recently, HD has been associated to tau aggregation, and therefore $\left[{ }^{18} \mathrm{~F}\right]-\mathrm{AV}-1451$ PET was performed in patients highlighting the implication of tau pathology in HD. ${ }^{28}$ However, no metal-based probes have been reported so far.

Amyotrophic Lateral Sclerosis (ALS), the most common motor disease, is a devastating and fatal adult-onset neurodegenerative disorder characterized by progressive degeneration of both upper motor neurons in the motor cortex and lower motor neurons in the spinal cord and brainstem. ${ }^{29}$ Hallmarks of ALS include protein aggregates mainly found in spinal motor neurons which can consist of cytostatin C, transferrin, neurofilament-rich hyaline aggregates, TDP-43 and mutant SOD-1. Mutant SOD-1 proteins aggregate to a greater extent than the normal wild-type SOD1 protein. $^{30}$ Some mutations arise from oxidative stress, which comes from an imbalance of the reactive oxygen and nitrogen species. The resulting free radicals have been previously shown to play a major role in $\mathrm{ALS}^{31}$ On the other hand, accumulation of TDP-43 in the cytoplasm directly contributes to the development of ALS due to their abnormal localization in the mitochondria, where TDP-43 binds to mitochondrial DNA. In fact, the mislocalization of TDP-43 to the cytoplasm also represents a key pathological feature of other major neurodegenerative diseases, including Alzheimer's disease, Parkinson's disease and Huntington's disease, ${ }^{32}$ showing once more the conspicuous similarities of these diseases. About $35-50 \%$ ALS patients show amyloid deposition, even without dementia. $\left[{ }^{11} \mathrm{C}\right]-\mathrm{PiB}$ and $\left[{ }^{18} \mathrm{~F}\right]$-florbetaten have been used in patients, but only a small number showed increased tracer uptake. $^{29}$

ALS has been diagnosed based on decreased $\left[{ }^{18} \mathrm{~F}\right]-\mathrm{FDG}$ uptake as well as by indirect cerebral blood flow brain dysfunction quantification, using $\left[{ }^{15} \mathrm{O}\right]-\mathrm{H}_{2} \mathrm{O}$ PET and $\left[{ }^{99 \mathrm{~m}} \mathrm{Tc}\right] \mathrm{d}, 1-\mathrm{HMPO}$ or $\left[{ }^{99 \mathrm{~m}} \mathrm{Tc}\right] \mathrm{ECD}$ SPECT. $\left[{ }^{18} \mathrm{~F}\right]$-DOPA PET and $\left[{ }^{123} \mathrm{I}\right]$-IPT SPECT are used for striatal presynaptic dopaminergic functioning; and $\left[{ }^{11} \mathrm{C}\right]$-flumazenil is used as biomarker for neuronal loss. Several probes have been developed allowing the assessment of neuroinflammation, excitotoxicity and synaptic density. Mitochondrial dysfunction and oxidative stress can be evaluated by the use of $\left[{ }^{62} \mathrm{Cu}\right]$ ATSM $\left(\left[{ }^{62} \mathrm{Cu}\right]\right.$-diacetyl-bis(N4methylthiosemicarbazone)), a PET radioligand that will be retained in cells displaying redox imbalance due to copper reduction to $\mathrm{Cu}(\mathrm{I}) .^{29}$ Towner et al have reported on another indirect method of assessing the effect of oxidative stress by MRI, using an anti-DMPO probe, which consists of an 
anti-DMPO antibody covalently bound to an albuminGdDTPA-biotin (DTPA = diethylenetriaminepentaacetic acid) MRI contrast agent. Free radicals generated from oxidative stress can be tagged by 5,5-dimethyl-1-pyrroline $\mathrm{N}$-oxide (DMPO), that form DMPO-radical adducts, targeted by the antibody used. ${ }^{31}$

Cerebral Amyloid Angiopathy (CAA), a major factor in intracerebral hemorrhage and vascular cognitive impairment is characterized by the deposition of amyloid aggregates in the walls of cerebral vasculature. Imaging probes capable of selective binding to $A \beta$ deposited in the walls of the cerebral vasculature and differentiating CAA from $A D$ are highly desired. To detect $C A A$ but not $A D$ senile plaques, low brain uptake of the imaging probe is favorable.

likuni et al reported a series of $\left[{ }^{99 \mathrm{~m}} \mathrm{Tc}\right] \mathrm{hydroxamamide}$ complexes with a multivalent amyloid ligand, and utilized stilbene and benzothiazole as ligands for amyloid aggregates. These compounds are believed to hardly cross the $B B B$ in vivo, and their high binding affinity for $A B$ aggregates is important for imaging CAA. ${ }^{33}$ Jaruszewski et al have designed theragnostic nanovehicles capable of targeting cerebrovascular amyloid (CVA). The nanovehicles were loaded with GdDTPA for MRI or with ${ }^{125}$ I for SPECT detection, respectively. In addition, they carried either antiinflammatory or anti-amyloidogenic molecules such as curcumin or immunosuppressants such as dexamethasone, which were previously shown to reduce cerebrovascular inflammation. Specific targeting to CVA deposits was achieved via the anti-amyloid antibody (IgG4.1) grafted on the surface of the nanovehicles. ${ }^{34}$ Kung et al have developed a series of ${ }^{68} \mathrm{Ga}$-labelled complexes for PET imaging based on a bivalent polypegylated styrylpyridine conjugated to a N,N'-Bis[2-hydroxy-5(carboxyethyl)benzyl]ethylenediamine- $\mathrm{N}, \mathrm{N}^{\prime}$-diacetic acid (HBED). These probes were originally designed to detect $A \beta$ deposits in the brain, but failed to efficiently cross the BBB and were then proposed as CAA probes. Preliminary results to map $A \beta$ aggregates in blood vessels of CAA patients were very promising. ${ }^{32}$

Type 2 Diabetes. Diabetes mellitus is one of the most common metabolic disorders characterized by chronic hyperglycemia resulting from defects in insulin secretion, insulin action, or both. About $90 \%$ of diabetic patients suffer from type 2 diabetes (T2D). This pathology is characterized by amyloid deposition in pancreatic islets (islet amyloid), formed from islet amyloid polypeptide (IAPP), also known as amylin. Amylin is a 37 amino acid protein, co-secreted with insulin in response to food intake. Islet amyloid formation is closely associated with $\beta$-cell dysfunction and a reduction of $\beta$-cell mass in diabetic patients.

Yashimura et al reported a ${ }^{125}$ I-labeled pyridyl-benzofuran (PBF) derivative $A \beta$ SPECT probe, $\left[{ }^{125} \mathrm{I}\right]-\mathrm{IPBF}$, for the visualization of amylin. This probe binds to amylin with a $\mathrm{K}_{\mathrm{i}}$ in the $\mathrm{nM}$ range and binds to islet amyloids in sections of human pancreas tissue. ${ }^{35}$ More recently, the same authors have described two [ ${ }^{99 \mathrm{~m}} \mathrm{Tc}$ ] probes for amylin targeting: the probes are PBF derivatives conjugated to a ${ }^{99 m}$ Tc-chelating moiety via a triethylene glycol spacer. The two bifunctional chelating ligands, iminodiacetic acid (IDA) and $\mathrm{N}, \mathrm{N}-$ dipicorylamine (DPA), easily form ${ }^{99 m}$ Tc tricarbonyl complexes. The IDA-based probe shows higher affinity for amylin aggregates and binds to human pancreas sections. This is the first metal-based probe successfully validated in vivo, showing uptake in amylin aggregates in the living mouse pancreas. ${ }^{36}$

Very recently, it has been reported that T2D can exacerbate neurodegenerative processes. T2D promotes Alzheimer's disease, namely through $A \beta$ and hyperphosphorylated tau accumulation, which induce neuronal degeneration including inflammatory and oxidative processes. Colocalized mixed amylin and $A \beta$ deposits were observed in human brain post-mortem, suggesting a potential ability of amylin to infiltrate the brain, promoting $A \beta$ deposition in the brain. Moreover, $A \beta$-deposits, elevated tau expression and increased hyperphosphorylation have also been observed in pancreas of T2D patients. ${ }^{37}$

Alzheimer's Disease. Among all misfolded-protein based pathologies, Alzheimer's disease has been the most investigated in terms of both mechanistic understanding and imaging probe development. AD biomarkers providing clinically useful information are either related to the molecular pathophysiology of the disease or to neurodegeneration, such as synaptic dysfunction and atrophy. The main hallmark of $A D^{\prime} s$ molecular pathophysiology is the presence of amyloid aggregates. The amyloid- $\beta$ ( $A \beta$ ) peptide is formed by the cleavage of the misregulated transmembrane amyloid precursor protein (APP), by $\beta$ - (instead of the normal $\alpha-$ ) and $\gamma$-secretases, yielding $A \beta$ species containing predominantly 39-42 amino acid residues. The longer $A \beta$-species, particularly $A \beta_{1-40}$ and $A \beta_{1-42}$, are released from the cell membrane and aggregate into soluble oligomers in the extracellular space. These oligomers, which are thought to be neurotoxic via an incompletely understood mechanism, in turn aggregate into larger insoluble $\beta$-sheet fibrils (8-10nm), and ultimately into the dense fibrillary amyloid plaques seen in $A D .^{13}$ Moreover, it has been reported that oligomers of $A \beta_{1-40}$ form parallel $\beta$-sheets while $A \beta_{1-42}$ oligomers lack the $\beta$ sheet secondary structure, which contributes to the different toxicity of these species. ${ }^{7}$

\section{In vitro detection of $\boldsymbol{A} \beta$ aggregates}

The fluorescent dyes Congo Red, Chrysamine-G, acridine orange and Thioflavins $S$ and $T$ have been first used to detect $A \beta$ plaques in histopathological post-mortem studies. These compounds bind the $\beta$-sheet structure of $A \beta$ aggregates and have been later widely used as scaffolds for 
imaging probes. They are relatively planar, hydrophobic aromatic molecules that interact with and bind to the cross$\beta$ sheet structure found in all amyloid fibrils; but are unable to cross the blood-brain barrier, partly due to their ionic charge. ${ }^{11,18}$ Later, phosphorescent rhenium and ruthenium complexes were also described as probes for staining and monitoring $A \beta$ fibril aggregation. The ligands used are based on polypyridyl, dipyridophenazine, 1,10phenanthroline or stilbene-like-4-(1-naphthyvinyl)pyridine analogue structures. ${ }^{18,} 19$ These complexes exhibit strong spin-orbit coupling promoted by the heavy-metal ions, yielding intense phosphorescent emissions with long-lived fluorescent life-times.

\section{PET imaging probes for $A \beta$ aggregates}

The first human PET imaging was published already in 2004 with ${ }^{11} \mathrm{C}$-PiB. Although ${ }^{11} \mathrm{C}$-PIB has never entered clinical use because of the short half-life of ${ }^{11} \mathrm{C}$, three $\left[{ }^{18} \mathrm{~F}\right.$-labelled agents have been clinically approved and others are in clinical trials (Figure 2). The field of non-metal based PET

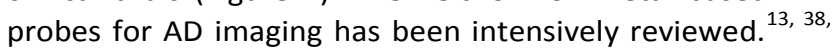
39

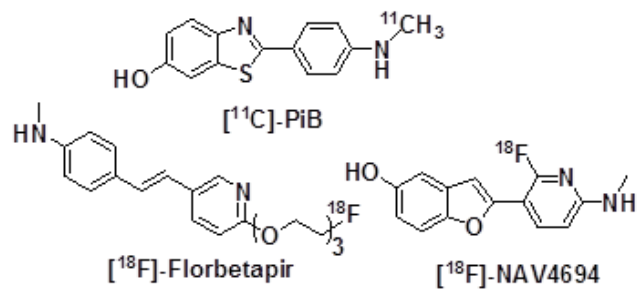

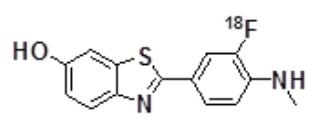

$\left[{ }^{18} \mathrm{~F}\right]$-Fluoremetanol

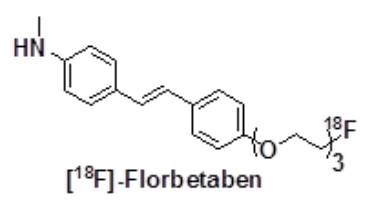

$\left[{ }^{18} \mathrm{~F}\right]$-Florbetaben
Figure 2: Structure of PET tracers for $A \beta$ aggregates.

Metal-based PET radiocomplexes offer the combined advantage of using longer lived isotopes $\left({ }^{68} \mathrm{Ga}\left(\mathrm{t}_{1 / 2}=1.1 \mathrm{~h}\right)\right.$, ${ }^{64} \mathrm{Cu}\left(\mathrm{t}_{1 / 2}=12.7 \mathrm{~h}\right)$ or $\left.{ }^{89} \mathrm{Zr}\left(\mathrm{t}_{1 / 2}=78.4 \mathrm{~h}\right)\right)$ and tuning the ligand properties for optimized targeting. Although ${ }^{68} \mathrm{Ga}$ has a rather short half-life $(1.1 \mathrm{~h})$, its easy availability from a ${ }^{68} \mathrm{Ge} /{ }^{68} \mathrm{Ga}$ generator in a relatively inexpensive way makes this isotope attractive for PET imaging. For $A \beta$ imaging, Ono et al. proposed the ${ }^{68} \mathrm{Ga}$ complex of DOTA conjugated with a 2-phenylbenzofuran (BF), via a propyl linker (DOTA-C3-BF; DOTA = 1,4,7,10-tetraazacyclododecane-1,4,7,10tetraacetic acid, Figure 3 ). This probe binds to $A \beta_{1-42}$ aggregates with an affinity in the $\mathrm{nM}$ range, confirmed by in vitro staining of $A \beta$ plaques from brain sections of Tg2576 mice. Biodistribution studies in wild type mice revealed though a low brain uptake of ${ }^{68}$ GaDOTA-C3-BF with 0.45 $\% \mathrm{ID} / \mathrm{g}$ at $2 \mathrm{~min}$ and $0.16 \% \mathrm{ID} / \mathrm{g}$ at $60 \mathrm{~min}$ post-injection. ${ }^{40}$
Mishra et al. reported a DTPA conjugated to two chalcone units via an amide linker (DT(Ch) 2 , Figure 3 ). The ${ }^{68} \mathrm{Ga}$ complex showed high affinity to $A \beta_{1-42}$ aggregates and had an increased brain uptake of $1.24 \% \mathrm{ID} / \mathrm{g}$ at $2 \mathrm{~min}$ and 0.20 $\% I D / g$ at $60 \mathrm{~min}$ post-injection in normal mice, likely due to its higher lipophilicity. ${ }^{41}$ Complexes based on curcumin derivatives were also reported; all forming complexes with 1:2 metal-to-ligand ratio (Figure 3). ${ }^{68} \mathrm{Ga}(\mathrm{CUR})_{2}{ }^{+}$, ${ }^{68} \mathrm{Ga}(\mathrm{DAC})_{2}{ }^{+}$, and ${ }^{68} \mathrm{Ga}(\mathrm{bDHC})_{2}$ showed high affinity to $A \beta$ when incubated with synthetic $\beta$-amyloid fibrils; ${ }^{42}$ and ${ }^{\text {nat }} \mathrm{Ga}(\mathrm{CUR})_{2}$ binds to amyloid- $\beta$ plaques in human brain tissue (fluorescent studies). ${ }^{43}$ Nevertheless, none of these probes was evaluated in vivo. We have also investigated ${ }^{68} \mathrm{Ga}$ complexes of three DOTA derivatives conjugated to a $\mathrm{PiB}$ unit via different linkers (vide infra). ${ }^{44}$

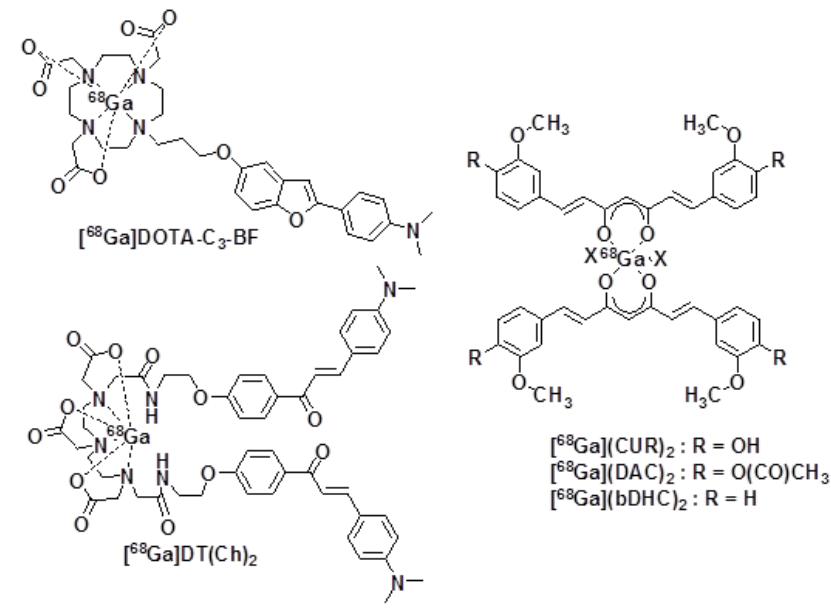

Figure 3: Structure of ${ }^{68} \mathrm{Ga}$ complexes for $\mathrm{A} \beta$ detection.

${ }^{64} \mathrm{Cu}$ presents a more attractive half-life of $12.7 \mathrm{~h}$. Donnelly et al. have reported a series of ${ }^{64} \mathrm{Cu}$-probes based on the bis(thiosemicarbazone) ligand family (Figure 4), known to form stable and membrane permeable copper complexes. The ${ }^{64} \mathrm{Cu}$-labelled derivative $\left[{ }^{64} \mathrm{Cu}\right]-\mathrm{GTSM}$ showed higher brain uptake in APP/PS1 mice model of amyloid pathology when compared with control animals, and higher APP/PS1 mice brain uptake than $\left[{ }^{64} \mathrm{Cu}\right]-\mathrm{ATSM}$ which is a hypoxia imaging probe in clinical trials for human applications. Based on these promising results, the same authors moved on towards an improvement of the brain uptake, and developed hybrid ligands by conjugating thiosemicarbazone structures to $A \beta$ plaque targeting groups: trans-stilbene (L1), benzothiazole (L2) and styrylpyridine (L3 and 4) (Figure 4). The radiocomplex ${ }^{64} \mathrm{CuL1}$ had a rather high brain uptake in APP/PS1 mice, but was difficult to radiolabel. Compound ${ }^{64} \mathrm{CuL} 2$ does not bind to $A \beta$ and ${ }^{64} \mathrm{CuL} 3-4$ show low brain uptake. ${ }^{18}$ Ono et al. reported on two ${ }^{64} \mathrm{Cu}$-labelled benzofuran derivatives, cyclen-C3-BF and DOTA-C3-BF (Figures 3 and 4). ${ }^{40}$ As previously found for the ${ }^{68} \mathrm{Ga}$ analogues, the ${ }^{64} \mathrm{Cu}$ complexes have low brain uptake in normal mice at 2 min post-injection $(0.33 \%$ and $0.36 \% \mathrm{ID} / \mathrm{g}$ 
respectively) and similar uptake at $30 \mathrm{~min}(0.18 \%$ and 0.17 \%ID/g respectively). ${ }^{45}$

The long half-life of ${ }^{89} \mathrm{Zr}$ (78.4h) offers the possibility of antibody-targeted PET imaging. A ${ }^{89} \mathrm{Zr}$ labelled monoclonal antibody, [ $\left.{ }^{89} \mathrm{Zr}\right] \mathrm{Df}-\mathrm{Bz}-J R F / A \beta N / 25$, for the immuno-PET imaging of $A \beta$ was recently reported. The bifunctional chelator $p$-isothiocyanatobenzyl-desferrioxamine (Df-BzNCS) was coupled to the $\mathrm{N}$-terminal end-specific mAb directed against the full-length human $A \beta$ epitope (JRF/A $\beta N / 25)$. The probe binds to $A \beta_{1-40}$ with a $K_{d}$ in the $n M$ range. Biodistribution studies in wild type mice showed modest brain uptake $(0.5 \pm 0.07 \% \mathrm{ID} / \mathrm{g}$ at $1 \mathrm{~h})$ and slow brain clearance $(0.36 \pm 0.06 \% \mathrm{ID} / \mathrm{g}$ at $48 \mathrm{~h})$. The BBB crossing and brain uptake was also confirmed by ex vivo autoradiography. ${ }^{46}$

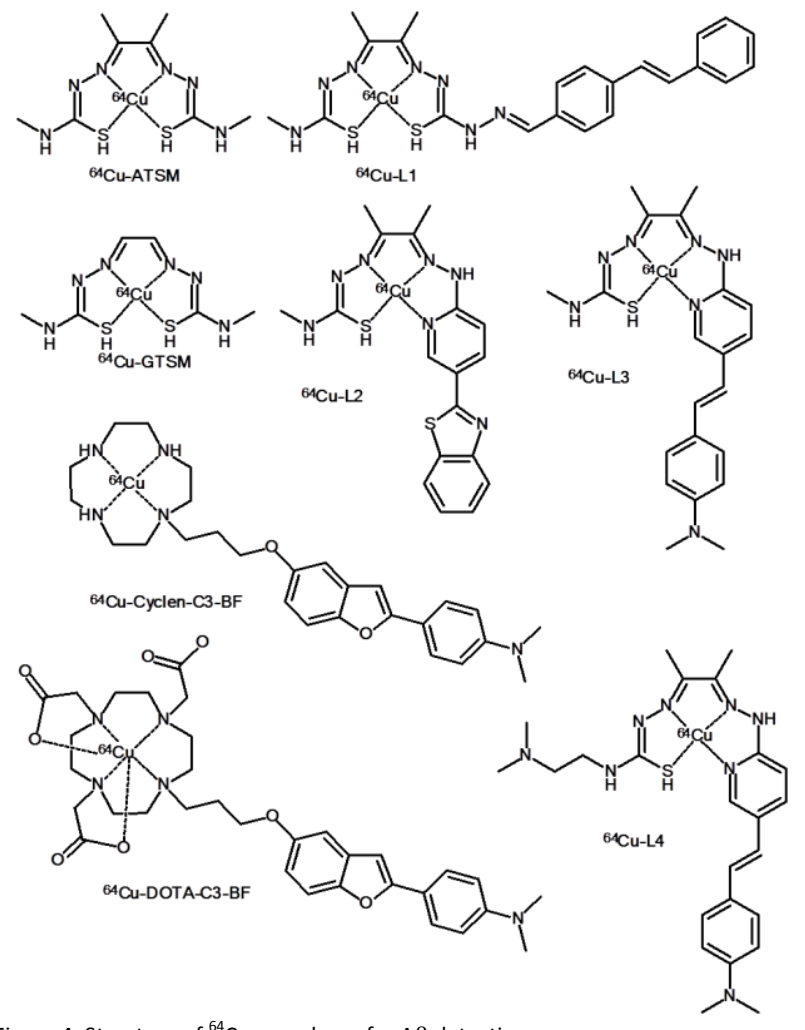

Figure 4: Structure of ${ }^{64} \mathrm{Cu}$ complexes for $\mathrm{A} \beta$ detection.

\section{SPECT imaging probes for $A \beta$ aggregates}

Metal-based radiocomplexes reported for $A \beta$ SPECT imaging involve ${ }^{99 m_{T}}\left(t_{1 / 2}=6 h\right)$ and ${ }^{111}$ In $\left(t_{1 / 2}=67.3 \mathrm{~h}\right)$. ${ }^{99 m} \mathrm{Tc}$ is the most used SPECT isotope, due to its ideal halflife (6h) and energy $(140 \mathrm{KeV})$ and its availability. ${ }^{99 \mathrm{~m}} \mathrm{Tc}-$ complexes have been studied for $A \beta$ targeting and reviewed. ${ }^{18,19}$ The large majority of the chelators are tetradentate $\mathrm{N}_{2} \mathrm{~S}_{2}, \mathrm{~N}_{2} \mathrm{O}_{2}$ or $\mathrm{N}_{3} \mathrm{O}$ ligands conjugated to benzothiazoles, benzofurans, flavones, chalcone, curcumin, naphthalene, dibenzylideneacetone and stilbene units. Among these, a 2-arylbenzothiazole derivative conjugated to a bis(aminoethanethiol) and complexed with ${ }^{99 \mathrm{~m}} \mathrm{Tc}$ (Figure 5, [ $\left.{ }^{99 \mathrm{~m}} \mathrm{Tc}\right] \mathrm{L5}$ ), showed highest brain uptake $2.11 \%$ ID/g at 2 min post-injection in normal mice $(0.62 \% \mathrm{ID} / \mathrm{g}$ at
$60 \mathrm{~min}$ ). This complex was further studied in rhesus monkeys, consisting in the first SPECT imaging in nonhuman primate for $A \beta$ detection (Figure 5). The semiquantitative data obtained (brain uptake of about $1 \%$ ID at 0-10 mins and $\approx 0.7 \%$ ID at $30-40$ mins) confirmed the promising results observed in the murine model. ${ }^{47}$
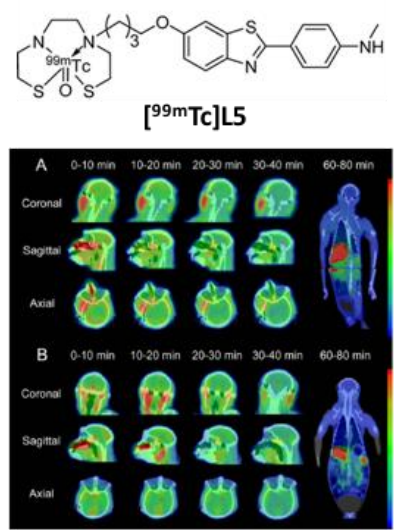

Figure 5: Structure of $\left[{ }^{99 \mathrm{~m}} \mathrm{Tc}\right] \mathrm{L5}$ (a) and SPECT images of $\left[{ }^{99 \mathrm{~m}} \mathrm{Tc}\right] \mathrm{L5}$ in rhesus monkeys (A: 4 years old, male; B: 27 years old, female); SPECT images are overlaid on individual co-registered CT images (b). Adapted with permission from ref. [47]

Thanks to its long half-life, ${ }^{111}$ In is also adapted to antibody targeting. Pardridge et al. have reported a DTPA-[N-biotin]$A \beta_{1-40}$ conjugate which was labeled with ${ }^{111}$ In and further coupled to a BBB targeting system, comprised of a peptidomimetic $M A b$ and an avidin or streptavidin moiety. The binding of $\left[{ }^{111}\right.$ In]DTPA-[N-biotin]-A $\beta_{1-40}$ to amyloid plaques of $A D$ in autopsy tissue sections was demonstrated by film and emulsion autoradiography. ${ }^{48}$ More recently, Weerd et al. have conjugated the bifunctional chelator $p$ SCN-Bz-DTPA to a VHH-Fc fusion protein, a llama single domain antibody fragment which targets amyloid plaques. Nevertheless, the ${ }^{111}$ In-VHH-Fc-DTPA did not cross the BBB and no $A \beta$ binding was detected either in control or in double transgenic APPswe/PS1dE9 mice. ${ }^{49}$

\section{NIRF imaging probes for $A \beta$ aggregates}

A series of molecules have been described for in vivo imaging of $A \beta$ plaques in animal models, capable of realtime monitoring of the progress of $A D$ in transgenic mice with intact cranium. NIR imaging is a versatile and sensitive method for studying the potential effectiveness of anti-AD drug candidates in small animals. The large majority of the NIRF probes relies on the increase of fluorescence or on the shift of emission maxima upon binding to aggregated $A \beta$ proteins. NIAD-4, which combines chemical features of Congo Red and Thioflavin-T, presents a remarkable red shift and a 400-fold fluorescence enhancement upon binding to $A \beta$ aggregates in vitro (with $K_{D} \approx n M$ ). This first NIRF probe reported (2005), ${ }^{50}$ was tested in transgenic $A D$ mice with a cranial window. It crosses the $\mathrm{BBB}$ and allows for in vivo detection in $A \beta$ plaques, confirmed by histologic ex-vivo studies. Other non-metal based NIRF probes for AD imaging in mice with intact cranium have been reported 
elsewhere. ${ }^{51-55}$ A coumarin-quinoline conjugate with a turnon NIR fluorescence that specifically targets $A \beta_{1-42}$ aggregates with selectivity over other biomacromolecules (HSA and DNA) and more importantly over toxic protein aggregates of tau, $\alpha$-Syn and IAPP, has been recently reported. This probe is a promising candidate for the development of in vitro and in vivo methods for clinical diagnosis of $A D$ in distinction from tauopathies and mixed dementia. ${ }^{56}$

\section{MRI in AD's disease}

In the absence of any CA, MR contrast allowing the visualization of mature, large ( $50 \mu \mathrm{m}$ diameter) individual amyloid plaques might be provided by sufficiently high iron accumulation, which leads to hypo-intense spots in $T_{2}, T_{2}$ * or susceptibility-weighted images. ${ }^{57-62}$ These experiments require high magnetic fields ( $7 \mathrm{~T}$ or more) and long acquisition times impracticable in clinical MRI. Moreover, not all plaques contain iron and this approach is limited to advanced stages of AD.

The detection of plaques weakly loaded with iron requires the use of exogenous CAs. Despite the enormous success of CAs for imaging the brain, liver, kidney or the vascular system, the development of imaging probes for the detection of $A \beta$ amyloid brain deposits has been limited and reached only the preclinical stage, mainly due to the low sensitivity of MRI relative to nuclear techniques. To be clinically helpful for $A \beta$ plaque detection in early $A D$ patients, MRI CAs, besides the general properties described above, should readily cross the blood-brain-barrier (BBB), accumulate sufficiently in the brain and bind specifically and selectively to $A \beta$ deposits. These remain currently major obstacles to molecular MR imaging in AD detection.

Non-specific, commercial CAs, such as GdDOTA

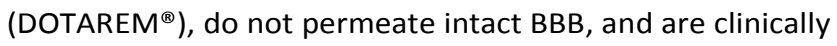
used to evaluate $B B B$ leakage in multiple sclerosis and glioma. ${ }^{63}$ Amyloid deposits in the brain of $A D$ transgenic mice have been detected by MRI after intracerebroventricular injection of GdDOTA, showing that if small and non-specific CAs reach the brain tissue, the amyloid deposits can be imaged. Upon administration, the hydrophilic GdDOTA complex diffuses rapidly throughout the brain parenchyma but does not interact with the highly hydrophobic $A \beta$ plaques, which are observed as hypointense spots in $T_{1}$-weighted images. ${ }^{64}$ Transient opening of the BBB with application of unfocussed ultrasound and microbubbles have also been proposed to allow brain entry of CAs. ${ }^{65}$

Although ${ }^{1} \mathrm{H}$-based images are the current mainstream of $\mathrm{MRI}$, other nuclei, in particular ${ }^{19} \mathrm{~F}$ can be also used to create MR images. The development of ${ }^{19} \mathrm{~F}$ MRI contrast agents for $A \beta$ detection has been reviewed recently, highlighting probes based on curcumin and styrylbenzoxazole derivatives, which have shown brain uptake in transgenic mouse models. ${ }^{66}{ }^{19} \mathrm{~F} \mathrm{MRI}$ visualization of $A \beta$ plaques has been achieved in transgenic mice. Despite the lack of background signal in ${ }^{19} \mathrm{~F} \mathrm{MRI}$, the intrinsic low sensitivity led to low resolution images, even at high probe doses.

\section{$A \beta$-targeted iron oxide nanoparticles}

The high $r_{2}$ relaxivities, thus high sensitivity of superparamagnetic iron oxide nanoparticles (SPIONs) have encouraged their use for AD imaging. ${ }^{67,}{ }^{68}$ Their disadvantage is that the intrinsic dark signals produced by $\mathrm{T}_{2}$ CAs can be confused with other hypointense areas such as bleeding, calcification, or metal deposition, which makes diagnosis difficult, leading to false positives. ${ }^{69}$ Iron oxide nanoparticles have been surface-functionalized with various $A \beta$-targeting vectors and used to visualize $A D$ plaques in transgenic mice. These include nanoparticles conjugated with modified human $A \beta_{1-40}$ or $A \beta_{1-42}$ peptides via putrescine or PEG. ${ }^{70-72}$ The low $B B B$ permeability of these probes required the use of adjuvants such as mannitol to transiently open the BBB, which prevents any human application. Particles were also functionalized with low molecular weight molecules such as derivatives of Rhodamine, Congo Red, or a lypophylic DDNP-carboxy derivative. $^{73,74}$ These probes kept their affinity to $A \beta$ plaques in vitro, but in vivo $\mathrm{T}_{2}{ }^{*}$ negative contrast was only visible in $A D$ transgenic mouse brains upon mannitol injection. Other studies include SPION-sialic acid derivative glyconanoparticles $^{75}$ and SPION-curcumin conjugates stabilized by PEG-PLA block polymer. ${ }^{76}$ The presence of PEG at the NPs surface was claimed to increase blood circulation time and facilitate BBB crossing via transcytosis. ${ }^{77}$ Other targeting strategies include conjugation with $A \beta$ specific peptides selected in a phage display, with binding affinity in the $\mu \mathrm{M}$ range. ${ }^{78}$ Again, in vivo $\mathrm{T}_{2}{ }^{*}$-weighted $\mathrm{MRI}$ plaque detection in $A D$ transgenic mice required mannitol coadjuvant injection.

\section{A $\beta$-targeted Gd-chelates}

Gd-complexes have been linked to targeting moieties including small molecules, peptides as well as antibodies. The first $A \beta$ targeted $\mathrm{Gd}^{3+}$-based MRI CA was reported by Poduslo et al. already fifteen years ago. A GdDTPA complex was conjugated to human $A \beta_{1-40}$ or $A \beta_{1-42}$ peptides modified with the polyamine putrescine in order to improve $B B B$ crossing. ${ }^{79}$ Imaging of $A D$ plaques in transgenic mice was achieved; however, it required the use of mannitol to open the BBB as well as long MRI scan times and high magnetic field $(7 \mathrm{~T})$. Later, the molecular design was improved by using synthetic modified $A \beta$ derivatives as targeting moiety. ${ }^{79,80}$ The same research group conjugated GdDOTA with $\mathrm{pF}\left(\mathrm{ab} \mathrm{b}_{2}\right)_{2} 4.1$, a putrescine modified antibody fragment of the monoclonal antibody, IgG4.1, raised against the fibrillar human amyloid protein $A \beta_{42}$. It was previously 
shown that the presence of putrescine increased BBB permeability of the antibody fragment, while the in vitro binding ability to $A \beta$ peptides and amyloid plaques was retained. ${ }^{81}$ Incubation of AD mouse brain slices with this CA resulted in selective enhancement of individual plaques on $\mathrm{T}_{1}$-weighted spin-echo MR images. ${ }^{82}$ The same antibody fragment was linked to smart nanovesicles made of polymeric chitosan NPs which could also cross the BBB and bind selectively and efficiently to $A \beta$ plaques. ${ }^{83}$ Austen et al have reported a series of GdDOTA-small peptide conjugates which bind to $\beta$-amyloid, but only crossed the BBB when adding a cationic cell penetration sequence and using microparticle assisted ultrasound activation. ${ }^{84}$ Among small molecular vectors, Congo Red (CR) was used in the CR-BSA$(\text { GdDTPA })_{n}$ conjugate (BSA = bovine serum albumin). Targeting was demonstrated by immunohistochemistry in brain sections from APP/PS1 transgenic mice. The authors suggested that CR-BSA-(Gd-DTPA)n could be used as a potential fluorescence and MR multi-modal imaging probe to display individual senile plaques in $A D .^{85}$

A library of sixteen small $\mathrm{Gd}^{3+}$-based CAs were synthesized using a building block strategy to investigate structureactivity relationships regarding physicochemical properties such as relaxivity and binding affinity to the $A \beta$ aggregates. Three blocks were used to modulate the CA structures: (i) the Gd(III) chelates GdDOTA or GdPCTA (PCTA $=3,6,9,15-$ tetraaza bicyclo[9.3.1]-pentadeca-1(15),11,13-triene-3,6,9triacetic acid), (ii) the biovectors (2-arylbenzothiazole, 2arylbenzoxazole and stilbene derivatives) and (iii) the linkers (neutral, positive and negative with several lengths). ${ }^{86}$ A large majority of the CAs were found to form micelles in water but not in serum, suggesting an important binding to plasma proteins such as HSA. At $1.5 \mathrm{~T}$, relaxivities in water were $r_{1}{ }^{\text {na }}=5.5-12.3 \mathrm{mM}^{-1} \mathrm{~s}^{-1}$ for the monomers and $r_{1}{ }^{a}=7.8-17.4 \mathrm{mM}^{-1} \mathrm{~s}^{-1}$ for the aggregates. Although an overall negative charge of the complex, either in the Gd(DOTA) moiety or in the linker, improved the solubility (above $5 \mathrm{mM}$ ), it had a negative effect on the binding to $A \beta$ plaques. Long linkers separating the complex and the $A \beta$ targeting moiety improved the affinity for $A \beta$ aggregates. The complex with the highest affinity, Gd(DOTA-Lys s $_{3}$-BTA) $(\mathrm{BTA}=$ (2-(4-N-methylaminophenyl) benzothiazole $))$, had $\mathrm{a}$ positively charged linker with three lysine residues. None of the compounds could cross the BBB in an in vitro model.

Curcumin (CUR) has also been used as targeting moiety either in small molecule conjugates with GdDTPA $^{87}$ or in a poly( $\beta$-L-malic) acid (PMLA) system decorated with GdDOTA. This latter was used to stain $A \beta$ plaques in ex vivo human and mouse brains with monitoring in fluorescence microscopy or MRI. ${ }^{88}$

We have used PiB derivatives as biovector for $A \beta$ targeting in a modular approach to create a set of low molecular weight $\mathrm{Gd}^{3+}$-based CAs. ${ }^{89-91}$ These probes consist of an imaging moiety formed by stable $\mathrm{Gd}^{3+}$ complexes of bifunctional derivatives of DO3A-monoamide (DO3A= 1,4,7,10-tetraazacyclo dodecane-1,4,7-triacetic acid) or DOTAGA $\quad(1,4,7,10$-tetraazacyclododecane-1,4,7-triacetic acid-10-glutaric acid) $\left(L_{i}, i=6-9\right.$, Figure 6$)$, bound through different neutral spacers to the amino group of PiB .

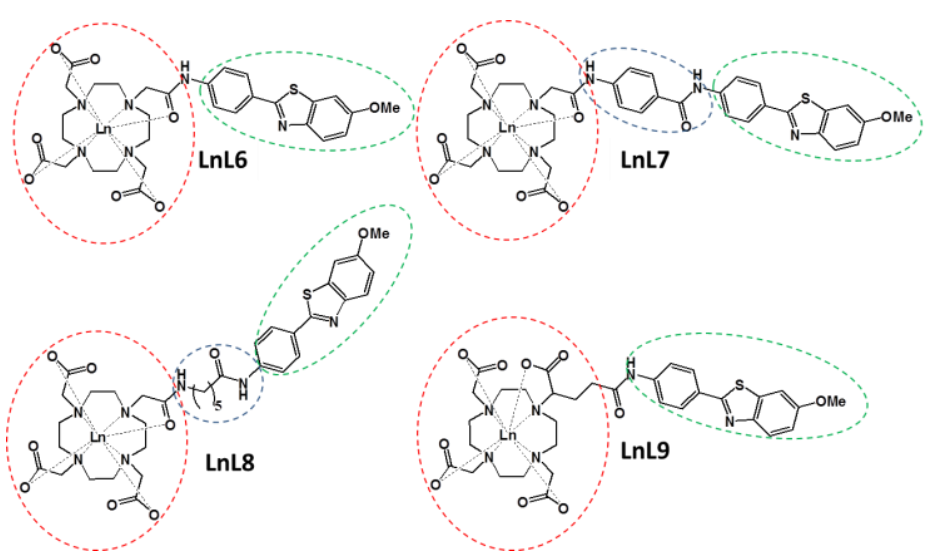

Figure 6: Modular structure of PiB-derivative complexes: units responsible for imaging (red), targeting moiety (green) and spacer (blue).

The ligands L6, L7 and L8 form neutral complexes and differ in the nature and size of the spacer, affecting their overall lipophilicity, while L9 forms a negatively charged complex. The metal chelating unit can efficiently coordinate, besides $\mathrm{Gd}^{3+}$ or any other $\mathrm{Ln}^{3+}$, a variety of metal ions that can act as imaging agents in different modalities, such as ${ }^{111} \mathrm{In}^{3+}$ in SPECT or ${ }^{68} \mathrm{Ga}^{3+}$ for PET.

A water proton relaxometric assessment of micelle formation in aqueous solution showed that the amphiphilic $\mathrm{Gd}\left(\mathrm{L}_{\mathrm{i}}\right)$ chelates undergo micellar aggregation in aqueous solution, with critical micellar concentrations, $\mathrm{cmc}$, in the 1.5- $0.7 \mathrm{mM}$ range. These $\mathrm{cmc}$ values are as low as those of other amphiphilic $\mathrm{Gd}^{3+}$ complexes comprising relatively long $\left(C_{14}\right)$ lipophilic tails, ${ }^{92}$ showing that the aromatic structures in $\mathrm{GdL}_{\mathrm{i}}$ efficiently promote micellar aggregation. These micelles are, in major part, expected to dissociate in vivo when injected, due to probe dilution and binding to plasma proteins like HSA. The relaxivities at $40 \mathrm{MHz}$ and 25 ${ }^{\circ} \mathrm{C}$ of the non-associated form, $r_{1}{ }^{\text {na }}=6.1-7.9 \mathrm{mM}^{-1} \mathrm{~s}^{-1}$, are typical of medium sized complexes with one inner-sphere water molecule, while in the micellar form they attain considerably higher values, $r_{1}{ }^{a}=13.8-22.30 \mathrm{mM}^{-1} \mathrm{~s}^{-1}{ }^{90,91}$

The molecular parameters controlling the relaxivity of the $\mathrm{GdL}_{\mathrm{i}}$ complexes were determined via a combined ${ }^{17} \mathrm{O} N M R$ and ${ }^{1} \mathrm{H}$ Nuclear Magnetic Relaxation Dispersion (NMRD) study (Table 2). ${ }^{17} \mathrm{O} N M R$ data are useful as they give independent access to the water exchange rate, $\mathrm{k}_{\mathrm{ex}}$, and the rotational correlation time, $\tau_{R} \cdot{ }^{1} H$ NMRD plots were obtained for the monomer as well as for the aggregated forms (Figure 7). A detailed description of their rotational dynamics was achieved by using the Lipari-Szabo treatment to analyze proton relaxation rates. It provided rotational correlation times for global $\left(\tau_{\mathrm{g}}\right)$ and local internal $\left(\tau_{\mathrm{l}}\right)$ 
motions and the order parameter $\mathrm{S}^{2}$. Interestingly, as compared to the analogous neutral complexes, $\mathrm{GdL}_{\mathrm{i}}(\mathrm{i}=6$ 8), the negative charge in GdL9 induces the formation of smaller micelles with a significant rigidity, which is reflected by slower and more restricted local motion of the $\mathrm{Gd}^{3+}$ centers, and also evidenced by higher relaxivities at $20-60$ $\mathrm{MHz}$.

Table 2. Parameters characterizing water exchange and rotational motion. The water exchange rate, Kex, was calculated from ${ }^{17} \mathrm{O}$ NMR data, while rotational correlation times were obtained from the analysis of NMRD data below and above the $\mathrm{cmc}$ for the monomer and micellar form, respectively.

\begin{tabular}{|c|c|c|c|c|c|}
\hline & \multicolumn{2}{|c|}{ Monomer } & \multicolumn{3}{|c|}{ Micellar form } \\
\hline & $\begin{array}{c}k_{e x}{ }^{<y 0} \\
{\left[10^{6} s^{-1}\right\rceil}\end{array}$ & $\begin{array}{c}\tau_{\mathrm{RH}}{ }^{2{ }^{30}} \\
{[\mathrm{ps}]}\end{array}$ & $\begin{array}{l}\tau_{\mathrm{g}}{ }^{2 \mathrm{O}} \mathrm{C} \\
\text { [ns] }\end{array}$ & $\begin{array}{l}\tau^{290} \\
{[p s]}\end{array}$ & $s^{2}$ \\
\hline $\mathrm{GdL6}^{\mathrm{a}}$ & & 130 & 12 & 105 & 0.12 \\
\hline $\mathrm{GdL7}^{\mathrm{a}}$ & & 150 & n.d. & n.d. & n.d. \\
\hline $\mathrm{GdL}^{\mathrm{a}}$ & 2.8 & 141 & 8 & 102 & 0.09 \\
\hline GdL9 $^{D}$ & 9.7 & 145 & 3.1 & 640 & 0.22 \\
\hline GdDOTA $^{c}$ & 4.1 & 77 & - & - & - \\
\hline
\end{tabular}

n.d. $=$ not determined; ${ }^{\mathrm{a}}$ ref ${ }^{90} ;{ }^{\mathrm{b}} \mathrm{ref}^{91} ;{ }^{\mathrm{c}} \mathrm{ref}^{93}$

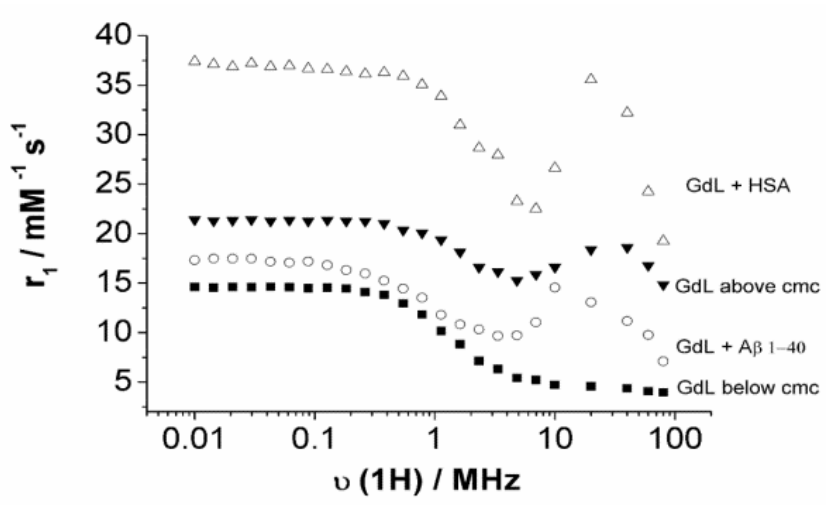

Figure 7: ${ }^{1} \mathrm{H}$ NMRD profiles of GdL9 at: $0.2 \mathrm{mM}(\boldsymbol{\nabla}), 5 \mathrm{mM}(\boldsymbol{\nabla}), 0.2 \mathrm{mM}$ in the presence of $0.2 \mathrm{mM} \mathrm{A} \beta_{1-40}$ (0) $0.2 \mathrm{mM}$ in the presence of $0.2 \mathrm{mM} \mathrm{HSA}(\Delta)(0.05 \mathrm{M}$ HEPES; $\mathrm{pH} 7.4, \mathrm{~T}=310 \mathrm{~K}$ ). Reproduced with permission from ref. 89.

All the $\mathrm{GdL}_{\mathrm{i}}$ complexes interact with serum albumin, reflected by the remarkable increase of relaxivity at intermediate fields in the presence of HSA (Figure 7). On one hand, strong albumin binding has a positive effect of preventing quick elimination of the agent from the body, but on the other hand, it reduces the BBB permeability of the agent. The binding affinity of $\mathrm{GdL}_{i}$ to HSA has been assessed by Proton Relaxation Enhancement (PRE) measurements. Assuming one binding site in HSA $(n=1)$, binding constants were calculated which increase from $K_{\mathrm{a}}=$
$0.25 \mathrm{mM}$ for GdL8 to $0.91 \mathrm{mM}$ for GdL6 and $6.53 \mathrm{mM}$ for GdL9. The one order of magnitude higher affinity of GdL9 to HSA can be accounted for its negative charge.

We have used a variety of experimental techniques to explore the interaction of the lanthanide complexes with the $A \beta_{1-40}$ amyloid peptides including surface plasmon resonance (SPR), saturation transfer difference NMR (STDNMR), circular dichroism (CD), dynamic light scattering (DLS) and transmission electron microscopy (TEM). In the Surface Plasmon Resonance (SPR) study, we used an immobilization protocol for $A \beta_{1-40}$ which allows for probing the aggregated state of the peptide in solution. The fitting of the SPR plots to a simple 1:1 Langmuir binding isotherm gave $K_{\mathrm{D}}$ values in the $67-170 \mu \mathrm{M}$ range. Table 4 compares the $K_{\mathrm{D}}$ values obtained by SPR and other techniques for the interaction of different $\mathrm{PiB}$ conjugated $\mathrm{Ln}^{3+}$ complexes and small benzothiazole molecules with aggregated $A \beta_{1-40}$. The $K_{\mathrm{D}}$ for the binding of the negatively charged $\mathrm{Gd}\left(\mathrm{L}_{4}\right)$ is close or slightly higher than those obtained for the neutral LaL6 and $\mathrm{La}(\mathrm{L} 7$, indicating that the presence of a negative charge does not improve the affinity of the complexes to the aggregated peptide. The conjugation of a metal chelate markedly reduces the binding affinity of the $\mathrm{PiB}$ to $A \beta_{1-40}$ aggregates, which is then two orders of magnitude lower than that of the positively charged ThT, and five orders of magnitude lower than that of the neutral PiB.

Table 3. Binding affinities of small molecules to $A \beta_{1-40}$

\begin{tabular}{|c|c|c|c|}
\hline Molecule & $\begin{array}{l}K_{\mathrm{D}}(\mu \mathrm{M}) \\
\text { det by SPR }\end{array}$ & $\begin{array}{l}K_{\mathrm{D}}(\mu \mathrm{M}) \\
\text { det by STD-NMR }\end{array}$ & Ref. \\
\hline LaL6 & 170 & 160 & 94 \\
\hline LaL8 & 67 & 80 & 94 \\
\hline GdL9 & 194 & n.d. ${ }^{a}$ & 91 \\
\hline $\mathrm{ThT}^{\mathrm{b}}$ & 0.79 & & 95 \\
\hline$\left[{ }^{11} \mathrm{C}\right]-\mathrm{PiB}{ }^{\mathrm{c}}$ & 0.0047 & & 96 \\
\hline
\end{tabular}

Dissociation constants were also determined by STD-NMR and were in excellent agreement with the values obtained by SPR (Table 3). The group epitope mapping, also performed by STD-NMR, evidenced that the benzothiazole moiety and the methoxy group are the major actors in the interaction with the aggregated $A \beta_{1-40}$. The higher STD effect for Gd-L9 also confirms the important contribution of the linker to the affinity. The interaction of $\operatorname{GdLi}(i=6,8,9)$ with the non-aggregated ${ }^{15} \mathrm{~N}-\mathrm{A} \beta_{1-40}$ peptide was monitored by ${ }^{1} \mathrm{H}-{ }^{15} \mathrm{~N}$ Heteronuclear Single Quantum Coherence 
(HSQC) NMR. These studies suggest a weak but nonnegligible interaction of the GdL9 complex with $A \beta_{1-40}$ in the monomer state, in contrast to the negligible binding observed for the neutral complexes.

The time-dependent aggregation of $A \beta_{1-40}$, relevant for understanding the molecular origins of $A D$, has been monitored in the presence of increasing amounts of the complexes: in far UV CD spectroscopy, the bands measured are very sensitive to changes in the secondary structure of proteins, while DLS and TEM give us information on the size and shape of the aggregates (Figure 8). Altogether these results are coherent and evidence that, despite their relative structural similarities; the complexes influence differently the aggregation process. While natural fibril formation is slightly promoted by GdL6 and GdL9, it is remarkably inhibited by GdL8. ${ }^{94}$
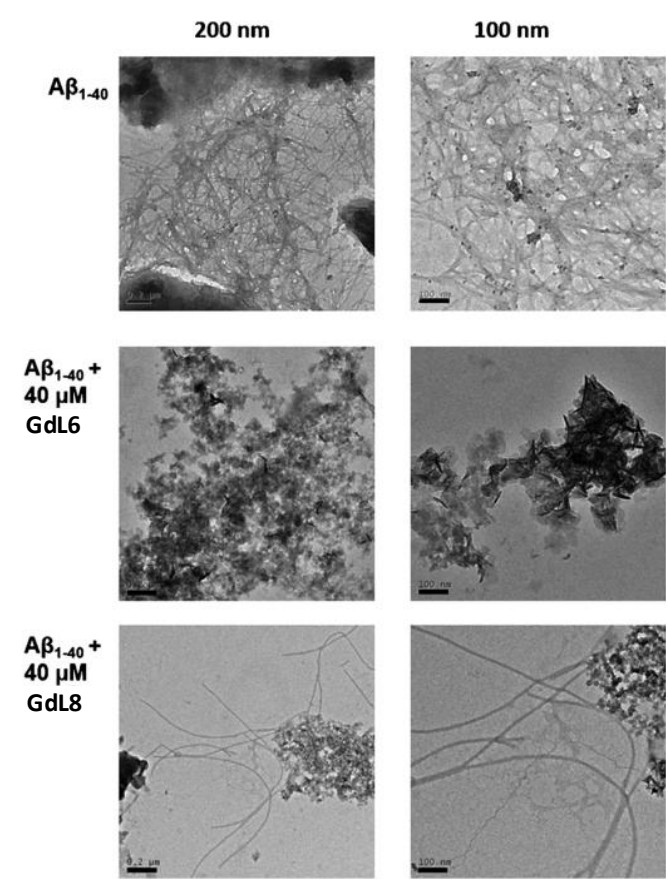

Figure 8: TEM images after $20 \mathrm{~d}$ of incubation of $40 \mathrm{~mm} \mathrm{Ab1-40} \mathrm{in} \mathrm{the} \mathrm{absence}$ (first row) or in the presence of $40 \mathrm{~mm} \mathrm{GdL6}$ (second row) and $40 \mathrm{~mm}$ GdL8 (third row). The bars correspond to $200 \mathrm{~nm}$ (left column) or $100 \mathrm{~nm}$ (right column). Reproduced with permission from ref. 94.

The ability of EuL6 to interact ex vivo with senile plaques in human brain slices of $A D$ patients was evaluated by taking advantage of the fluorescent properties of the PiB unit. This complex shows comparable distribution pattern and binding intensity to the senile plaques as the ones obtained with PiB or thioflavin-S (also fluorescent). The specificity of EuL6 for the amyloid deposits was evidenced by a doublefluorescence staining with a specific antibody (Figure 9).

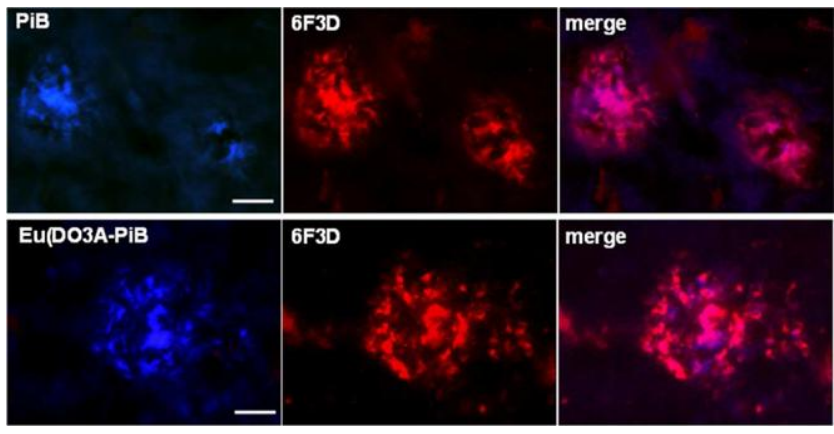

Figure 9: Micrographs illustrating the colocalization of PiB or EuL6 and 6F3Dantibody labelling of amyloid deposits of postmortem human brain tissue of an $A D$ patient: the co-localization is confirmed by the magenta colour in the merge images; scale bar $=20 \mu \mathrm{m}$. Reproduced with permission from ref. 89 .

Complexation of L6-9 with appropriate radiometals might allow their use for SPECT and PET imaging, but also the evaluation of the in vivo BBB penetration. Labeling of L6 with ${ }^{111} \operatorname{In}^{3+}$ (>96\% radiochemical purity) has shown a rather promising brain uptake on adult male Swiss control (no amyloid deposits). The brain uptake has been obtained by performing biodistribution studies with $\left[{ }^{111} \mathrm{In}\right] \mathrm{L6}$, which revealed an uptake of 0.36 and $0.5 \% \mathrm{ID} / \mathrm{g}$ in the cortex and cerebellum at $2 \mathrm{~min}$ post-injection; while at $30 \mathrm{~min}$, it was 0.11 and $0.21 \% \mathrm{ID} / \mathrm{g}$, respectively. The labeling of the ligands $\mathrm{L} 6-8$ with ${ }^{68} \mathrm{Ga}^{3+}$ has revealed to be more challenging and lower radiochemical yields were achieved (11-42\%). Nevertheless, the successful purification of the labeling reaction crude allowed the study of all 3 radiocomplexes on adult C57/BL6 control mice and on 18month-old APP/PS1 mice. Analysis of the $\mu$-PET imaging showed similar values of brain uptake for $\left[{ }^{68} \mathrm{Ga}\right]$ L6 or $\left[{ }^{68} \mathrm{Ga}\right] \mathrm{L} 7$ at $2 \mathrm{~min}$ post-injection in both animal models (0.9$1.1 \%$ ID/cc). This differed greatly for $\left[{ }^{68} \mathrm{Ga}\right] \mathrm{L} 8$, for which a 2.5 -fold greater BBB permeability $(\approx 1.3 \% \mathrm{ID} / \mathrm{cc}$ at $2 \mathrm{~min}$ ) was observed in the APP/PS1 model by comparison with control mice $(\approx 0.5 \% \mathrm{ID} / \mathrm{cc}$ at $2 \mathrm{~min})$. Overall, these studies showed that despite their promising features, these structures have to be further improved, namely regarding their lipophilic properties, leading to better BBB permeability and therefore higher brain uptake values.

Brain delivery of these Gd-complexes could be improved via conjugation to nanocarriers capable of translocating across the BBB - either per se or upon targeting to transporters expressed in the brain vasculature. Carbon nanotubes (CNTs) display unique physico-chemical properties suitable for use in nanomedicine applications, including large surface area allowing conjugation of therapeutic and imaging molecules. Previous in vitro and in vivo proof-ofconcept studies demonstrated that functionalized multiwalled carbon nanotubes ( $f$-MWNTs) are capable of crossing an intact BBB. ${ }^{97}$ Aiming at improving brain delivery of our $\mathrm{PiB}$ derivatives, some of the complexes were non- 
covalently conjugated to f-MWNTs. ${ }^{98}$ MWNT characterization was performed using thermogravimetric analysis (TGA), while conjugation was evaluated using inductively coupled plasma mass spectrometry (ICP-MS) and fluorimetry. Radiolabelling with ${ }^{111}$ In allowed quantification of in vivo biodistribution and brain uptake by SPECT/CT and $y$-scintigraphy. The whole-brain uptake values were $\sim 1.16 \% \mathrm{ID} / \mathrm{g}$ of tissue at $30 \mathrm{~min}$ post injection, corresponding to a tenfold increase as compared to those for the free chelates without $f$-MWNTs.

$\mathrm{Gd}^{3+}$ containing multimodal AGuIX nanoparticles have been also conjugated with specific targeting units for the diagnosis of different pathologies involving amyloidose. ${ }^{99}$,

100 AGuIX particles are made of a polysiloxane network surrounded by several GdDOTAGA chelates and have a diameter smaller than $5 \mathrm{~nm}$. Additional free ligands are available at the surface of AGuIX and can be used to chelate radioisotopes (e.g., ${ }^{68} \mathrm{Ga}^{3+}$ or ${ }^{111} \mathrm{In}^{3+}$ ). The particles were functionalized with LPFFD and KLVFF, two small peptides derived from the sequence of $A \beta_{1-42}$ and highly specific for $A \beta$ amyloid fibrils. ${ }^{99}$ The capacity of such nanoparticles grafted with peptide to discriminate among different amyloid proteins was tested with $A \beta_{1-42}$ fibrils and with mutated-(V30M) transthyretin (TTR) fibrils, implicated in familial amyloid polyneuropathy, another type of amyloidosis. Both functionalized nanoparticles interact with $A \beta(1-42)$ fibrils with equilibrium dissociation constant values of $350-400 \mu \mathrm{M}$, whilst they did not interact with V30M-TTR fibrils. This is in contrast to PiB, which is a general amyloid fibril marker and thus equally well interacts with both types of fibrils. AGuIX nanoparticles were also conjugated with the Pittsburgh compound $B$ and the nanobody B10AP. ${ }^{100}$ Their ability to target amyloid fibrils made of $\beta$-amyloid peptide, amylin or Val30Met mutated transthyretin formed in vitro or from pathological tissues was investigated by spectroscopic and biophysics techniques including fluorescence microscopy. Both probes interact with these three different amyloid fibrils, with the $\mathrm{Kd}$ being 10 micromolar and 10 nanomolar, for PiB- and B10AP-derived nanoparticles respectively. The amyloid deposits could be detected on pathological tissues. These functionalized nanoparticles are promising imaging tools for multimodal detection of different amyloid diseases, including $A D$, Type 2 diabetes mellitus and the familial amyloidotic polyneuropathy.

\section{Concluding Remarks}

There is increasing evidence that misfolded protein aggregation is implicated in many incapacitating diseases, including Amyotrophic Lateral Sclerosis, Cerebral Amyloid Angiopathy, Type II Diabetes, Parkinson's, Huntington's and Alzheimer's diseases, although the underlying mechanisms are not always fully elucidated. Molecular imaging probes detecting amyloidogenesis could greatly contribute to a better understanding of these pathologies, provide more accurate and early diagnosis, and could be also useful in monitoring novel treatment strategies. So far, imaging agents have been proposed for several misfolded proteinbased pathologies, Alzheimer's disease being the most widely investigated in this respect. In particular, recent years have witnessed the emergence of metal-based imaging probes for nuclear (PET and SPECT) and MR imaging modalities. Despite the first successful in vivo results in PET and SPECT imaging using amyloid-targeted metal complexes, further improvement in the molecular design of the probes is expected in order to meet the challenge of higher target affinity and specificity. As most of the amyloid-related pathologies concern the brain, one major challenge is to improve blood-brain barrier permeability. In general, all approaches typically applied to drugs destined for the central nervous system could be considered. These involve intracerebral and intracerebroventricular administration, intranasal delivery or blood-to-brain delivery, resulting from a transient disruption of the blood-brain-barrier induced by biological, chemical or physical stimuli (mannitol, magnetic heating, ultrasound). Vector-mediated blood-to-brain delivery has also great potential. In particular, nanomaterials are promising transporters across the intact BBB thanks to their capability to enter the brain capillary endothelial cells via endocytosis and transcytosis. ${ }^{101,102}$ While the brain delivery of metal-based probes in sufficient quantities is within easier reach for nuclear imaging, this issue is evidently more problematic in MRI. For $\mathrm{Gd}^{3+}$ complexes, the combination of different strategies might be an option to attain detectable brain concentrations. In this context, $\mathrm{Gd}^{3+-}$ based MRI probes seem to be more adapted to preclinical animal studies where intracerebral and intracerebroventricular administration or BBB opening might be also applicable, while the clinical translation of nuclear probes, requiring lower amounts of the probe to be delivered in the brain, is more realistic. Alternatively, amyloid-related pathologies not requiring brain delivery, such as Cerebral Amyloid Angiopathy or Type II Diabetes can more easily benefit from metal-based molecular imaging agents.

Finally, metal-based probes can be also valuable for studies aiming at a basic understanding of misfolded proteins. The versatile magnetic, optical and nuclear properties of metal ions open the possibility to use a large variety of biophysical techniques for such investigations. This potential is still to be fully explored.

\section{Conflict of interest}

There are no conflicts to declare.

\section{Acknowledgements}

Financial support of the Agence Nationale de la Recherche, France is acknowledged (ANR-16-CE18-0022-01). C.F.G.C.G 
thanks the financial support from the Fundação para a Ciência e Tecnologia (F.C.T., Portugal, project RECl/QEQQFI/0168/2012), and the European Regional Development Fund - FEDER (projects CENTRO-07-CT62-FEDER and GINOP-2.3.2-15-2016-00008).

\section{References}

1. C. M. Dobson, Nature, 2003, 426, 884-890.

2. P. Faller, C. Hureau and O. Berthoumieu, Inorganic Chemistry, 2013, 52, 12193-12206.

3. T. Vajda and A. Perczel, Journal of Peptide Science, 2014, 20, 747-759.

4. M. K. Siddiqi, P. Alam, S. K. Chaturvedi, Y. E. Shahein and R. H. Khan, Frontiers in Bioscience, 2017, 9, 1-20.

5. L. Huang, X. Liu, B. Cheng and K. Huang, Archives of Biochemistry and Biophysics, 2015, 568, 46-55.

$6 . \quad$ D. J. Selkoe, Nature Cell Biology, 2004, 6, 1054-1061.

7. S. A. Kotler, P. Walsh, J. R. Brender and A. Ramamoorthy, Chemical Society Reviews, 2014, 43, 6692-6700.

8. K. Berthelot, C. Cullin and S. Lecomte, Biochimie, 2013, 95, 12-19.

9. J. R. Brender, S. Salamekh and A. Ramamoorthy, Accounts of Chemical Research, 2012, 45, 454-462.

10. K. J. Korshavn, C. Satriano, Y. Lin, R. Zhang, M Dulchavsky, A. Bhunia, M. I. Ivanova, Y.-H. Lee, C. La Rosa, M. H. Lim and A. Ramamoorthy, Journal of Biological Chemistry, 2017, 292, 4638-4650.

11. V. L. Villemagne, Ageing Research Reviews, 2016, 30, 95-106.

12. C. Giacomelli, S. Daniele and C. Martini, Biochemical Pharmacology, 2017, 131, 1-15.

13. A. Mallik, A. Drzezga and S. Minoshima, Seminars in Nuclear Medicine, 2017, 47, 31-43.

14. S. R. Meikle, F. J. Beekman and S. E. Rose, Drug Discovery Today: Technologies, 2006, 3, 187-194.

15. S. A. Hilderbrand and R. Weissleder, Current Opinion in Chemical Biology, 2010, 14, 71-79.

16. A. E. Merbach, L. Helm and E. Toth, The Chemistry of Contrast Agents in Medical Magnetic Resonance Imaging, second edn., John Wiley \& Sons, Chichester, 2013.

17. M. Salerno and D. S. D. Porqueras, Coordination Chemistry Reviews, 2016, 327-328, 27-34.

18. D. J. Hayne, S. Lim and P. S. Donnelly, Chemical Society Reviews, 2014, 43, 6701-6715.

19. K. Chen and M. Cui, MedChemComm, 2017.

20. A. S. DeToma, S. Salamekh, A. Ramamoorthy and M. H. Lim, Chemical Society Reviews, 2012, 41, 608-621.

21. P. A. Broderick, L. Wenning and Y.-S. Li, Journal of Neural Transmission, 2017, 124, 57-78.

22. P. T. Kotzbauer, Z. Tu and R. H. Mach, Clinical and Translational Imaging, 2017, 5, 3-14.

23. U. Saeed, J. Compagnone, R. I. Aviv, A. P. Strafella, S. E. Black, A. E. Lang and M. Masellis, Translational Neurodegeneration, 2017, 6, 1-25.

24. M. Wang, M. Gao, Z. Xu and Q.-H. Zheng, Bioorganic \& Medicinal Chemistry Letters, 2017, 27, 1351-1355.

25. G. Pagano, F. Niccolini and M. Politis, Clinical Medicine, 2016, 16, 371-375
26. J. L. Eberling, K. D. Dave and M. A. Frasier, Journal of Parkinson's Disease, 2013, 3, 565-567.

27. J. Varley, D. J. Brooks and P. Edison, Alzheimer's \& Dementia, 2015, 11, 1110-1120.

28. K. Giehl, K. Reetz, I. Dogan, C. Werner, J. B. Schulz, J. Hammes, A. Drzezga and T. v. Eimeren, Basal Ganglia, 2017, 8, 1-22

29. S. M. A. Willekens, D. V. Weehaeghe, P. V. Damme and K. V. Laere, European Journal of Nuclear Medicine and Molecular Imaging, 2017, 44, 533-547.

30. D. A. Bosco, G. Morfini, N. M. Karabacak, Y. Song, F. Gros-Louis, P. Pasinelli, H. Goolsby, B. A. Fontaine, N. Lemay, D. McKenna-Yasek, M. P. Frosch, J. N. Agar, J.P. Julien, S. T. Brady and R. H. B. Jr, Nature Neuroscience, 2010, 13, 1396-1405.

31. R. A. Towner, N. Smith, D. Saunders, F. Lupu, R. SilasiMansat, M. West, D. C. Ramirez, S. E. Gomez-Mejiba, M. G. Bonini, R. P. Mason, M. Ehrenshaft and K. Hensley, Free Radical Biology and Medicine, 2013, 63 351-360.

32. W. Wang, L. Wang, J. Lu, S. L. Siedlak, H. Fujioka, J. Liang, S. Jiang, X. Ma, Z. Jiang, E. L. d. Rocha, M. Sheng, $\mathrm{H}$. Choi, P. H. Lerou, H. Li and X. Wang, Nature Medicine, 2016, 22, 869-878.

33. S. likuni, M. Ono, H. Watanabe, K. Matsumura, M Yoshimura, H. Kimura, H. Ishibashi-Ueda, Y. Okamoto, M. Ihara and H. Saji, Scientific Reports, 2016, 6, 25990.

34. K. M. Jaruszewski, G. L. Curran, S. K. Swaminathan, J. T. Rosenberg, S. C. Grant, S. Ramakrishnan, V. J. Lowe, J. F. Poduslo and K. K. Kandimalla, Biomaterials, 2014, 35, 1967-1976.

35. M. Yoshimura, M. Ono, H. Watanabe, H. Kimura and H. Saji, Scientific Reports, 2014, 4, 6155.

36. M. Yoshimura, M. Ono, H. Watanabe, H. Kimura and H. Saji, Bioconjugate Chemistry, 2016, 27, 1532-1539.

37. P. Bharadwaj, N. Wijesekara, M. Liyanapathirana, P. Newsholme, L. Ittner, P. Fraser and G. Verdile, Journal of Alzheimer's Disease, 2017, 59.

38. L. Zhu, K. Ploessl and H. F. Kung, Chemical Society Reviews, 2014, 43, 6683-6691.

39. W. Bao, H. Jia, S. Finnema, Z. Cai, R. E. Carson and Y. H. Huang, PET Clinics, 2017.

40. H. Watanabe, M. Ono, S. likuni, M. Yoshimura, K Matsumura, H. Kimura and H. Saji, Bioorganic \& Medicinal Chemistry Letters, 2014, 24, 4834-4837.

41. K. Chauhan, A. Datta, A. Adhikari, K. Chuttani, A. K. Singh and A. K. Mishra, Organic \& Biomolecular Chemistry, 2014, 12, 7328-7337.

42. M. Asti, E. Ferrari, S. Croci, G. Atti, S. Rubagotti, M. Iori, P. C. Capponi, A. Zerbini, M. Saladini and A. Versari, Inorganic Chemistry, 2014, 53, 4922-4933.

43. J. L. Lange, D. J. Hayne, P. Roselt, C. A. McLean, J. M. White and P. S. Donnelly, Journal of Inorganic Biochemistry, 2016, 162, 274-279.

44. D. Cressier, M. Dhilly, T. T. C. Pham, F. Fillesoye, F. Gourand, A. Maïza, A. F. Martins, J.-F. Morfin, C. F. G. C. Geraldes, É. Tóth and L. Barré, Molecular Imaging and Biology, 2016, 18, 334-343.

45. H. Watanabe, A. Kawasaki, K. Sano, M. Ono and H. Saji, Bioorganic \& Medicinal Chemistry, 2016, 24, 36183623. 
46.

J. Fissers, A.-M. Waldron, T. D. Vijlder, B. V. Broeck, D. J. Pemberton, M. Mercken, P. V. D. Veken, J. Joossens, K. Augustyns, S. Dedeurwaerdere, S. Stroobants, S. Staelens and L. wyffels, Molecular Imaging and Biology, 2016, 18, 598-605.

47. X. Zhang, P. Yu, Y. Yang, Y. Hou, C. Peng, Z. Liang, J. Lu, B. Chen, J. Dai, B. Liu and M. Cui, Bioconjugate Chemistry, 2016, 27, 2493-2504.

48. A. Kurihara and W. M. Pardridge, Bioconjugate Chemistry, 2000, 11, 380-386.

49. M. Rotman, M. M. Welling, M. L. v. d. Boogaard, L. G. Moursel, L. M. v. d. Graaf, M. A. v. Buchem, S. M. v. d. Maarel and L. v. d. Weerd, Nuclear Medicine and Biology, 2015, 42, 695-702.

50. E. E. Nesterov, J. Skoch, B. T. Hyman, W. E. Klunk, B. J. Bacskai and T. M. Swager, Angewandte Chemie International Edition, 2005, 44, 5452-5456.

51. M. Staderini, M. A. Martin, M. L. Bolognesi and J. C. Menendez, Chemical Society Reviews, 2015, 44, 18071819.

52. X. Zhang, Y. Tian, C. Zhang, X. Tian, A. W. Ross, R. D. Moir, H. Sun, R. E. Tanzi, A. Moore and C. Ran, Proceedings of the National Academy of Sciences, 2015, 112, 9734-9739.

53. X. Zhang, Y. Tian, Z. Li, X. Tian, H. Sun, H. Liu, A. Moore and C. Ran, Journal of the American Chemical Society, 2013, 135, 16397-16409.

54. H. Fu, P. Tu, L. Zhao, J. Dai, B. Liu and M. Cui, Analytical chemistry, 2016, 88, 1944-1950.

55. K. Zhou, H. Bai, L. Feng, J. Dai and M. Cui, Analytical chemistry, 2017, 89, 9432-9437.

56. K. Rajasekhar, N. Narayanaswamy, N. A. Murugan, K. Viccaro, H.-G. Lee, K. Shah and T. Govindaraju, Biosensors and Bioelectronics, 2017, 98, 54-61.

57. H. Benveniste, G. Einstein, K. R. Kim, C. Hulette and G. A. Johnson, Proceedings of the National Academy of Sciences, 1999, 96, 14079-14084.

58. J. C.R. Jack, M. Garwood, T. M. Wengenack, B. Borowski, G. L. Curran, J. Lin, G. Adriany, O. H. Gröhn, R. Grimm and J. F. Poduslo, Magnetic Resonance in Medicine, 2004, 52, 1263-1271.

59. S. P. Lee, M. F. Falangola, R. A. Nixon, K. Duff and J. A. Helpern, Magnetic Resonance in Medicine, 2004, 52, 538-544.

60. G. Vanhoutte, I. Dewachter, P. Borghgraef, F. V. Leuven and A. V. d. Linden, Magnetic Resonance in Medicine, 2005, 53, 607-613.

61. T. Nakada, H. Matsuzawa, H. Igarashi, Y. Fujii and I. L. Kwee, Journal of Neuroimaging, 2008, 18, 125-129.

62. M. Dhenain, N. E. T. E. Tayara, T. D. Wu, M. Guégan, A. Volk, C. Quintana and B. Delatour, Neurobiology of Aging, 2009, 30, 41-53.

63. M. Filippi and R. I. Grossman, Neurology, 2002, 58, 1147-1153.

64. A. Petiet, M. Santin, A. Bertrand, C. J. Wiggins, F. Petit, D. Houitte, P. Hantraye, J. Benavides, T. Debeir, T. Rooney and M. Dhenain, Neurobiology of Aging, 2012, 33, 1533-1544.

65. M. D. Santin, T. Debeir, S. L. Bridal, T. Rooney and M. Dhenain, Neuroimage, 2013, 79, 288-294.

66. I. Tooyama, D. Yanagisawa, H. Taguchi, T. Kato, K. Hirao, N. Shirai, T. Sogabe, N. F. Ibrahim, T. Inubushi and S. Morikawa, Ageing Research Reviews, 2016, 30, 85-94.

67. S. Laurent, D. Forge, M. Port, A. Roch, C. Robic, L. V. Elst and R. N. Muller, Chemical Reviews, 2008, 108, 2064-2110.

68. M. M. Lin, D. K. Kim, A. J. E. Haj and J. Dobson, IEEE Transactions on Nanobioscience, 2008, 7, 298-305.

69. N. Lee and T. Hyeon, Chemical Society Reviews, 2012, 41, 2575-2589.

70. Y. Z. Wadghiri, J. Li, J. Wang, D. M. Hoang, Y. Sun, H. Xu, W. Tsui, Y. Li, A. Boutajangout, A. Wang, M. d. Leon and T. Wisniewski, PLoS One, 2013, 8, e57097.

71. J. Yang, Y. Z. Wadghiri, D. M. Hoang, W. Tsui, Y. Sun, E. Chung, Y. Li, A. Wang, M. d. Leon and T. Wisniewski, Neuroimage, 2011, 55, 1600-1609.

72. Y. Z. Wadghiri, E. M. Sigurdsson, M. Sadowski, J. I. Elliott, Y. Li, H. Scholtzova, C. Y. Tang, G. Aguinaldo, M. Pappolla, K. Duff, T. Wisniewski and D. H. Turnbull, Magnetic Resonance in Medicine, 2003, 50, 293-302.

73. J. Zhou, H. Fa, W. Yin, J. Zhang, C. Hou, D. Hou, D. Zhang and H. Zhang, Materials Science \& Engineering C, Materials for Biological Applications, 2014, 37, 348355.

74. D. Zhang, H. B. Fa, J. T. Zhou, S. Li, X. W. Diao and W. Yin, Clinical Radiology, 2015, 70, 74-80.

75. H. Kouyoumdjian, D. C. Zhu, M. H. El-Dakdouki, K. Lorenz, J. Chen, W. Li and X. Huang, ACS Chemical Neuroscience, 2013, 4, 575-584.

76. K. K. Cheng, P. S. Chan, S. Fan, S. M. Kwan, K. L. Yeung, Y. X. Wáng, A. H. Chow, E. X. Wu and L. Baum, Biomaterials, 2015, 44, 155-172.

77. S. Ku, F. Yan, Y. Wang, Y. Sun, N. Yang and L. Ye, Biochemical and Biophysical Research Communications, 2010, 394, 871-876.

78. L. Larbanoix, C. Burtea, S. Laurent, F. V. Leuven, G. Toubeau, L. V. Elst and R. N. Muller, Neurobiology of Aging, 2010, 31, 1679-1689.

79. J. F. Poduslo, T. M. Wengenack, G. L. Curran, T. Wisniewski, E. M. Sigurdsson, S. I. Macura, B. J. Borowski and C. R. J. Jack, Neurobiology of Disease, 2002, 11, 315-329.

80. J. F. Poduslo, G. L. Curran, J. A. Peterson, D. J. McCormick, A. H. Fauq, M. A. Khan and T. M. Wengenack, Biochemistry, 2004, 43, 6064-6075.

81. J. F. Poduslo, M. Ramakrishnan, S. S. Holasek, M. Ramirez-Alvarado, K. K. Kandimalla, E. J. Gilles, G. L. Curran and T. M. Wengenack, Journal of Neurochemistry, 2007, 102, 420-433.

82. M. Ramakrishnan, T. M. Wengenack, K. K. Kandimalla, G. L. Curran, E. J. Gilles, M. Ramirez-Alvarado, J. Lin, M. Garwood, J. C.R. Jack and J. F. Poduslo, Pharmaceutical Research, 2008, 25, 1861-1872.

83. E. K. Agyare, G. L. Curran, M. Ramakrishnan, C. C. Yu, J. F. Poduslo and K. K. Kandimalla, Pharmaceutical Research, 2008, 25, 2674-2684.

84. B. Matharu, N. Spencer, F. Howe and B. Austen, Neuropeptides, 2015, 53, 63-70.

85. S. Li, H. He, W. Cui, B. Gu, J. Li, Z. Qi, G. Zhou, C.-M. Liang and X.-Y. Feng, The Anatomical Record, 2010, 293, 2136-2143. 
86. G. Bort, S. Catoen, H. Borderies, A. Kebsi, S. Ballet, G. Louin, M. Port and C. Ferroud, European Journal of Medicinal Chemistry, 2014, 87, 843-861.

87. S. M. Vithanarachchi and M. J. Allen, Chemical Communications, 2013, 49, 4148-4150.

88. R. Patil, P. R. Gangalum, S. Wagner, J. Portilla-Arias, H. Ding, A. Rekechenetskiy, B. Konda, S. Inoue, K. L. Black, J. Y. Ljubimova and E. Holler, Macromolecular Bioscience, 2015, 15, 1212-1217.

89. A. F. Martins, J.-F. Morfin, A. Kubíčková, V. Kubíček, F. Buron, F. Suzenet, M. Salerno, A. N. Lazar, C. Duyckaerts, N. Arlicot, D. Guilloteau, C. F. G. C. Geraldes and É. Tóth, ACS Med Chem, 2013, 4, 436440.

90. A. F. Martins, J.-F. Morfin, C. F. G. C. Geraldes and É. Tóth, Journal of Biological Inorganic Chemistry, 2014, 19, 281-295.

91. A. F. Martins, A. C. Oliveira, J.-F. Morfin, D. V. Laurents, É. Tóth and C. F. G. C. Geraldes, Journal of Biological Inorganic Chemistry, 2016, 21, 83-99.

92. E. Toth, L. Helm, K. E. Kellar and A. E. Merbach, Chemistry - A European Journal, 1999, 5, 1202-1211.

93. D. H. Powell, O. M. N. Dhubhghaill, D. Pubanz, L. Helm, Y. S. Lebedev, W. Schlaepfer and A. E. Merbach, Journal of American Chemical Society, 1996, 118, 9333-9346.

94. A. F. Martins, D. M. Dias, J. F. Morfin, S. Lacerda, D. V. Laurents, E. Toth and C. F. G. C. Geraldes, Chemistry-a European Journal, 2015, 21, 5413-5422.

95. R. L. Yona, S. Mazères, P. Faller and E. Gras, ChemMedChem, 2008, 3, 63-66.

96. Y. W. Chester A. Mathis, Daniel P. Holt, Guo-Feng Huang, Manik L. Debnath, and William E. Klunk Journal of Medicinal Chemistry, 2003, 46, 2740-2754.

97. P. M. Costa, M. Bourgognon, J. T. W. Wang and K. T. Al-Jamal, Journal of Controlled Release, 2016, 241, 200-219.

98. P. M. Costa, J. T. W. Wang, J. F. Morfin, T. Khanum, W. To, E. Toth and K. T. Al-Jamal, submitted.

99. M. Plissonneau, J. Pansieri, L. Heinrich-Balard, J. F. Morfin, N. Stransky-Heilkron, P. Rivory, P. Mowat, M. Dumoulin, R. Cohen, E. Allemann, E. Toth, M. J. Saraiva, C. Louis, O. Tillement, V. Forge, F. Lux and C. Marquette, Journal of Nanobiotechnology, 2016, 14.

100. J. Pansieri, M. Plissonneau, N. Stransky-Heilkron, M. Dumoulin, L. Heinrich-Balard, P. Rivory, J. F. Morfin, E. Toth, J. M. Saravia, E. Allemann, O. Tillement, V. Forge, F. Lux and C. Marquette, Nanomedicine, 2017, in press.

101. X. Li, J. Tsibouklis, T. Weng, B. Zhang, G. Yin, G. Feng, Y. Cui, I. N. Savina, L. I. Mikhalovska, S. R. Sandeman, C. A. Howel and S. V. Mikhalovsky, Journal of Drug Targeting, 2017, 25, 17-28.

102. P. K. Pandey, A. K. Sharma and U. Gupta, Tissue Barriers, 2016, 4, e1129476. 